\title{
Molecular mechanisms underlying the cholesterol- lowering effect of Ginkgo biloba extract in hepatocytes: a comparative study with lovastatin
}

Zuo-quan XIE ${ }^{1,2}$, Gai LIANG ${ }^{3}$, Lu ZHANG ${ }^{1,2}$, Qi WANG ${ }^{2}, Y_{i} Q^{2}$, Yang GAO ${ }^{2}$, Li-bo LIN², Sai YE ${ }^{2}$, Ji ZHANG ${ }^{1}$, Hui WANG ${ }^{3}$, Guoping ZHAO ${ }^{2,4}$, Qing-hua ZHANG ${ }^{1,2,4, *}$

${ }^{1}$ State Key Laboratory of Medical Genomics and Shanghai Institute of Hematology, Ruijin Hospital, Shanghai Jiaotong University School of Medicine, Shanghai 200025, China; ${ }^{2}$ National Engineering Center for Biochip at Shanghai and Shanghai Biochip Co Itd, Shanghai 201203, China; ${ }^{3}$ Department of Pharmacology, Basic Medical School of Wuhan University, Wuhan 430071, China; ${ }^{4}$ Shanghai-MOST Key Laboratory of Health and Disease Genomics, Shanghai 201203, China

\begin{abstract}
Aim: To explore the molecular mechanisms underlying the cholesterol-lowering effect of a Ginkgo biloba extract (GBE).
Methods: Enzyme activity, cholesterol flux and changes in gene expression levels were assessed in cultured hepatocytes treated with GBE or lovastatin.

Results: GBE decreased the total cholesterol content in cultured hepatocytes and inhibited the activity of HMG-CoA reductase, as determined by an in vitro enzyme activity assay. In addition, GBE decreased cholesterol influx, whereas lovastatin increased cholesterol influx. GBE treatment induced significant increases in the expression of cholesterogenic genes and genes involved in cholesterol metabolism, such as SREBF2, as determined by cDNA microarray and real-time RT-PCR. Furthermore, INSIG2, LDLR, LRP1, and $L R P 10$ were differentially regulated by GBE and lovastatin. The data imply that the two compounds modulate cholesterol metabolism through distinct mechanisms.

Conclusion: By using a gene expression profiling approach, we were able to broaden the understanding of the molecular mechanisms by which GBE lowers cellular cholesterol levels. Specifically, we demonstrated that GBE exhibited dual effects on the cellular cholesterol pool by modulating both HMG-CoA reductase activity and inhibiting cholesterol influx.
\end{abstract}

Keywords: Ginkgo biloba extract; cholesterol; HMG-CoA reductase; influx; lovastatin; microarray

Acta Pharmacologica Sinica (2009) 30: 1262-1275; doi: 10.1038/aps.2009.126; published online 24 August 2009

\section{Introduction}

Ginkgo biloba extract (GBE) is being increasingly used as a dietary supplement for the treatment of a variety of neurological and cardiovascular disorders. The main active components of the standard GBE are flavonol glycosides ( $24 \%$ total volume) and terpene lactones $(\sim 6 \%)^{[1]}$. The mixture of biologically active ingredients present in GBE has pleiotropic physiological effects, including the inhibition of amyloidformation ${ }^{[2,3]}$, antioxidant activity ${ }^{[4,5]}$, anti-apoptosis activity ${ }^{[6]}$, effects on vasodilation ${ }^{[7]}$ and inhibition of platelet aggregation $^{[8,9]}$. Recently, studies have shown that GBE modulates

The original microarray data have been submitted to GEO (accession number GSE11830).

* To whom correspondence should be addressed.

E-mail qinghua_zhang@shbiochip.com

Received 2008-12-29 Accepted 2009-03-09 the metabolism of cholesterol. GBE decreased the blood cholesterol level in rats and rabbits fed a cholesterol-enriched $\operatorname{diet}^{[10-12]}$. In humans, GBE ingestion reduces the formation and size of atherosclerotic nanoplaques in high-risk cardiovascular patients and attenuates risk factors, including oxidized low-density lipoprotein (oxLDL)/low density lipoprotein (LDL) and lipoprotein $\mathrm{Lp}(\mathrm{a})^{[13]}$. These observations reveal the modulating effect of GBE on cholesterol metabolism; however, the underlying mechanisms remain undefined.

The liver is the major source of endogenous cholesterol biosynthesis and is largely responsible for the maintenance of blood cholesterol homeostasis. Therefore, we used two cultured human hepatocellular carcinoma cell lines, HepG2, and SK-HEP-1, in the present study to evaluate the cholesterollowering effect of GBE. In addition, we used lovastatin, a well-known cholesterol-lowering medication, as our positive control. To investigate the mechanisms underlying the 
cholesterol-lowering effect of GBE, we used a combination of experimental approaches, including enzyme activity and cholesterol flux assays, along with cDNA microarray and real time RT-PCR, to explore the gene regulation networks that are downstream of GBE treatment. Data presented here bring a new understanding to the molecular mechanisms by which GBE affects cholesterol metabolism.

\section{Materials and methods} Cell culture and treatment

GBE was provided by XingLing Pharmaceutical Co (Shanghai, China) as a standardized product that contains $\sim 24 \%$ flavonol glycosides, $\sim 6 \%$ terpene lactones (ginkgolides, bilobalide), and less than $\sim 5$ ppm ginkgolic acid. HepG2 cells were maintained in Minimum Essential Medium (MEM, Invitrogen) with 10\% fetal bovine serum (FBS) (JRH Biosciences). Cells were seeded in 6-well plates at a density of $4 \times 10^{5}$ cells per well. When the cells were about $70 \%$ confluent, the medium was replaced with medium containing $2 \%$ FBS for drug treatment experiments. For dose-response experiments, a variety of concentrations of GBE $(50,100$, and $200 \mu \mathrm{g} / \mathrm{mL})$ were used, and the cells were treated for $24 \mathrm{~h}$. For time course experiments, cells were treated for different times $(6,12,24$, and $48 \mathrm{~h}$ ) with either 200 $\mu \mathrm{g} / \mathrm{mL}$ of GBE or $0.5 \mu \mathrm{mol} / \mathrm{L}$ lovastatin. Control cells were treated with $0.1 \%$ DMSO (the vehicle) for the longest treatment time in the experiment. Treatments were identical for both the SK-HEP-1 and the HepG2 cell lines, with the exception that SK-HEP-1 cells were cultured in Dulbecco's modified Eagle's medium (DMEM, Invitrogen).

\section{Cellular cholesterol measurement}

Cellular total cholesterol was extracted as previously reported ${ }^{[14]}$ with slight modifications. Briefly, cells were harvested and washed twice with PBS, followed by resuspension in $1 \mathrm{~mL}$ isopropanol and sonication for $20 \mathrm{~min}$ at $4{ }^{\circ} \mathrm{C}$. After centrifugation at $9000 \times g$ for $10 \mathrm{~min}$ at $4{ }^{\circ} \mathrm{C}$, the supernatant was evaporated under a vacuum and the pellet was resuspended in $20 \mu \mathrm{L}$ isopropanol for cellular cholesterol measurement. The cholesterol was measured colorimetrically using a Total Cholesterol Detection Kit (Jiemen Bio-Tech, Shanghai, China). Additionally, the sediment fractions were lysed using a Mammalian Cell Extraction Kit (BioVision). Total protein levels were quantified by the Bradford method.

\section{HMG-CoA reductase enzymatic activity assay}

The activity of HMG-CoA reductase was measured according to a previously published method ${ }^{[15]}$ with slight modifications. Briefly, microsomes were prepared from the livers of rats. The assay was performed in a total volume of $120 \mu \mathrm{L}$ containing $500 \mathrm{nmol}$ NADPH (dissolved in $0.1 \mathrm{~mol} / \mathrm{L}$ triethanolamine and $10 \mathrm{mmol} / \mathrm{L}$ EDTA) and $100 \mu \mathrm{g}$ of microsomes. After a 5 min preincubation at $37{ }^{\circ} \mathrm{C}, 5.17 \mathrm{nmol}\left[{ }^{14} \mathrm{C}\right] \mathrm{HMG}-\mathrm{CoA}$ (GE Healthcare), with or without GBE or lovastatin, was added to the system (final concentration $38.3 \mu \mathrm{mol} / \mathrm{L}$ and $2.14 \mathrm{GBq} /$ mmol, respectively). After a $15 \mathrm{~min}$ incubation at $37^{\circ} \mathrm{C}$, the reaction was terminated by the addition of $30 \mu \mathrm{L}$ of $6 \mathrm{~mol} / \mathrm{L}$
$\mathrm{HCl}$. The samples were incubated for $15 \mathrm{~min}$ at $37^{\circ} \mathrm{C}$ to allow complete lactonization of the mevalonic acid, followed by centrifugation at $9000 \times g$ for $10 \mathrm{~min}$. The supernatants were spotted onto silica gel GF254 TLC plates, and the chromatograms were developed in benzene-acetone 1:1 (v/v). $\left[{ }^{14} \mathrm{C}\right] \mathrm{MVA}$ lactone (GE Healthcare) was used as a reference. The $\left[{ }^{14} \mathrm{C}\right]$ radioactivity was determined with a liquid scintillation counter (LS6500, Beckman-Coulter). HMG-CoA reductase activity was calculated as $\mu \mathrm{mol}$ of mevalonate generated per minute per mg of microsomes at $37^{\circ} \mathrm{C}$.

\section{Cholesterol influx and efflux assay}

Cholesterol influx and efflux assays were carried out according to the methods described by Yao et al ${ }^{[10]}$. For the cholesterol influx measurements, $2 \times 10^{5}$ HepG2 cells were seeded in $24-$ well plates and cultured in MEM plus 10\% FBS. When the cells reached $75 \%-80 \%$ confluence, the medium was replaced with $0.5 \mathrm{~mL}$ MEM containing $2 \%$ FBS and $0.2 \mu \mathrm{Ci}\left[1 \mathrm{a}, 2 \mathrm{a}(\mathrm{n})-{ }^{3} \mathrm{H}\right]$ cholesterol (GE Healthcare) and the presence or absence of either various concentrations of $\operatorname{GBE}(50,100$, and $200 \mu \mathrm{g} / \mathrm{mL})$ or lovastatin $(0.5 \mu \mathrm{mol} / \mathrm{L})$. After $24 \mathrm{~h}$ of treatment, the cells were washed with PBS twice and lysed in $200 \mu \mathrm{L}$ of $0.1 \mathrm{~mol} / \mathrm{L}$ $\mathrm{NaOH}$. Radioactivity was measured by a liquid scintillation counter (LS6500, Beckman-Coulter). Protein levels were quantified by the Bradford method.

For the efflux assay, $2 \times 10^{5}$ HepG2 cells were seeded in 24-well plates and cultured with MEM plus 10\% FBS and $0.2 \mu \mathrm{Ci}\left[1 \mathrm{a}, 2 \mathrm{a}(\mathrm{n})-{ }^{3} \mathrm{H}\right]$ cholesterol in each well for $48 \mathrm{~h}$. After incubation, the cells were washed twice with MEM plus $10 \%$ FBS and FBS-free medium. Then, the cells were treated with the indicated concentrations of GBE and lovastatin in $0.5 \mathrm{~mL}$ MEM plus $2 \%$ FBS for $24 \mathrm{~h}$. A volume of $200 \mu \mathrm{L}$ of medium was used to determine the level of radioactivity. Protein levels were quantified as described above.

\section{cDNA microarray}

After the time course experiments, cells were collected and total RNA was extracted using TRIzol reagent (Invitrogen), followed by purification on an RNeasy column (Qiagen) and quantified by UV absorption (Nanodrop). RNA quality was assessed with a 2100 Bioanalyzer and the RNA 6000 LabChipR (Agilent Technologies). The SBC homemade human cDNA microarray (Shanghai, China) contains 15552 spots, including 768 controls and 14784 probes. The probes represent 10379 known genes and 3022 ESTs. The microarray was made as previously described $^{[16]}$. An Agilent Low RNA Input Fluorescent Linear Amplification Kit (Agilent Technologies) was used for RNA linear amplification following the manufacturer's protocol. RNA samples from three wells of the vehicle treated group were pooled and used as a reference to label Cy3 (GE Healthcare). RNA from the drug treated cells was isolated in triplicate and labeled with Cy5 individually. Cy3- and Cy5labeled cRNA pools were mixed to hybridize to the microarrays. Hybridization and washes were performed using a standard protocol, followed by scanning on a Axon 4000B Scanner (Axon Instruments) ${ }^{[17]}$. 


\section{Data analysis}

Data analysis between and within the chip's normalization was performed by locally weighted scatter plot smoothing (LOWESS) regression ${ }^{[18]}$. Only genes present in greater than $80 \%$ of the samples were filtered out for further analysis. A total of 9510 genes/ESTs were selected out. The log2 ratio of each gene/EST is available at the following Web site: www. shbiochip.com/research/GBE/HepG2. Principal Components Analysis (PCA) was applied to distinguish between different groups. Gene expression profiling at each time point was analyzed with Significance Analysis of Microarray software (SAM, version 2.20) ${ }^{[19]}$ with One Class response type (FDR<0.01). Differentially expressed genes were chosen if they fit at least one of the following criteria: 1) genes were regulated in at least one time point by either GBE or lovastatin, 2) genes were differentially expressed between GBE and lovastatin treatment in at least one time point, or 3) gene expression levels were different among the different time points for either GBE or lovastatin. A total of 1264 regulated genes/ESTs were selected out and presented using a component plane presentation integrated self-organizing map (CPP-SOM $)^{[20]}$ with 12 neurons based on the gene expression profile. The online database KEGG (www.genome.jp/kegg) was applied to interpret the gene function pathway.

\section{Real-time RT-PCR}

Total RNA from each sample used for the microarray experiment was subjected to reverse transcription. Real-time RTPCR was conducted using an ABI PRISM 7300 Sequence Detector (Applied Biosystems) with SYBR green I fluorescent dye (Toyobo, Japan). The reactions were carried out in triplicate. GAPDH was used as an internal control. Gene expression was evaluated with threshold cycles. The gene names and PCR primer sequences are listed in Table S1.

\section{Western blot analysis}

Proteins were prepared with the Mammalian Cell Extraction Kit (BioVision). An aliquot of each sample (50 $\mu \mathrm{g})$ was subjected to SDS-polyacrylamide $(10 \%)$ gel electrophoresis and electro-transferred onto a PVDF membrane. After being blocked with $5 \%$ nonfat milk, the membranes were individually probed with the following primary antibodies for $2 \mathrm{~h}$ :

Table S1. Primer sequences of the genes subjected to real-time RT-PCR.

\begin{tabular}{|c|c|c|c|c|c|}
\hline Symbol & Genebank & Forward primer & Reverse primer & $\begin{array}{l}\text { Microarray } \\
\text { covering }\end{array}$ & $\begin{array}{l}\text { Array } \\
\text { detect }\end{array}$ \\
\hline ABCA1 & NM_005502 & AAGCTCTTTGCACTAGGATGGC & TGTAGCATGTTCCGGTGTTTCTC & $\mathrm{P}$ & ND \\
\hline ABCG5 & NM_022436 & GACTGCTCTGAACGTCTGAAATG & TTTCCAAATAACСАСАТGTCCC & NA & \\
\hline ABCG8 & NM_022437 & TCCTGCGGTGGTGTTTTG & CGATGAGGTAGATGGCGTA & NA & \\
\hline APOA1 & NM_000039 & ACCTAAAGCTCCTTGACAAC & CCTGCCACTTCTTCTGGA & $\mathrm{P}$ & $\mathrm{R}$ \\
\hline APOB & NM_000384 & AAGAACCTGTTAGTTGCTCTTAAGG & TTCTTCGTCGCAATGGCCT & NA & \\
\hline CYP7A1 & NM_000780 & GGATGTATTCTTTCTGCTACCGAG & CGCAGTCCTGAACATGTGAA & NA & \\
\hline DAF & NM_000574 & TTTAAAATGGTCCACAGCAGTC & ATAATATGCCACCTGGTACATC & NA & \\
\hline DHCR7 & NM_001360 & AGTCACCTTTACTAGTCCTTTGG & GTAAATGCAGCCTAATGACAG & $\mathrm{P}$ & $\mathrm{R}$ \\
\hline ELOVL6 & NM_024090 & TGCACTGGTATCACCACATCAC & TGCACGCCATAGTTCATAGTCA & $P$ & $\mathrm{R}$ \\
\hline NR1H4 & NM_005123 & TTTTGACGGAAATGGCAACC & TCAGAATGCCCAGACGGAAG & $\mathrm{P}$ & \\
\hline GAPDH & NM_002046 & TGACTTCAACAGCGACACCCA & САСССTGTTGCTGTAGCCAAA & $\mathrm{P}$ & IC \\
\hline HMGCR & NM_000859 & TAGGAGGCTACAACGCCCAT & ССАСССАCCGTTCCTATCTC & $\mathrm{P}$ & $\mathrm{R}$ \\
\hline IDI1 & NM_004508 & GGCTGAAAGCTGAGCTAGGA & TTTCATGTTCACCCCAGATAC & $\mathrm{P}$ & $\mathrm{R}$ \\
\hline IGFBP1 & NM_000596 & TGCCAAACTGCAACAAGAATG & TGGAGACCCAGGGATCCT & $\mathrm{P}$ & $\mathrm{R}$ \\
\hline INSIG2 & NM_016133 & AATGGCAACCAGCACCTC & CATGCACAGACACATTCTCTC & NA & \\
\hline KIAA0101 & NM_014736 & AACTCCCAAGTGGCAAAAAGG & TGTGTGATCAGGTTGCAAAGG & $\mathrm{P}$ & $\mathrm{R}$ \\
\hline LDLR & NM_000527 & GATTCATGTGGCAAGAACG & AGCTGAACTCACCGGATCG & $P$ & ND \\
\hline LRH1 & NM_205860 & TCGCCGATCAGAGCTCATA & САТTССТСТССАТGTATCTTCTA & NA & \\
\hline LRP1 & NM_002332 & GССТССАТССТААТСССТСТ & GGTTTCCAATCTCCACGTTCA & $\mathrm{P}$ & ND \\
\hline LXRA & NM_005693 & GACTTTGCTAAACAGCTACCC & CTGCTTTGGCAAAGTCTTC & $\mathrm{P}$ & ND \\
\hline MTTP & NM_000253 & TATATGCAGTATGCTACCCACAGC & GTACCAAATGAGATTTGAGAGAGGT & $\mathrm{P}$ & ND \\
\hline NPC1L1 & NM_013389 & САTCTCTATGGGAAGTGCGGT & CCACGTAGCTGAGGATGAC & $P$ & ND \\
\hline PCNA & NM_002592 & ATAAAGAGGAGGAAGCTGTTAC & AGAGAGTGGAGTGGCTTTTG & $\mathrm{P}$ & $\mathrm{R}$ \\
\hline SCAP & NM_012235 & CCAGTGGAGGACAAGATGGG & CAGGTAAGGGAGGTGACAT & NA & \\
\hline SCARB1 & NM_005505 & CATGAAATCTGTCGCAGGC & TTTGGCAGATGACAGGGAC & NA & \\
\hline SHP & NM_021969 & TGCCTGAAAGGGACCATC & ACTTCACACAGCACCCAGT & $\mathrm{P}$ & ND \\
\hline SLC35B1 & NM_005827 & GGGTCTTGGTCTTGATGCC & CCAAGAGATGTCACTGTTTGA & $\mathrm{P}$ & $\mathrm{R}$ \\
\hline SOAT1 & NM_003101 & GACTTGTCGTTACGTGTTTTAG & CAGTTTGGCTTCAAGTGAC & $\mathrm{P}$ & ND \\
\hline SREBF2 & NM_004599 & TCACTСССTGGGAAAGC & CAGTAGCAGGTCACAGGT & $P$ & ND \\
\hline
\end{tabular}

microarray covering: P, presented in the genelist of the microarray; NA, not included in the genelist of the microarray; array detect: R, regulation detected with microarray, ND, no regulation detected with microarray; IC, internal control used; blank, not presented in the microarray 
$\beta$-actin (1:5000, Abcam), HMGCR (1:800, sc-27578, Santa Cruz Biotechnologies), SREBP2 N-terminus (1:200, sc-8151, Santa Cruz Biotechnologies), and SREBP2 C-terminus (1:200, sc-13552, Santa Cruz Biotechnologies). Then, the membranes were incubated with a horseradish peroxidase (HRP) conjugated secondary antibody, either goat anti-mouse (1:4000, Sigma) or donkey anti-goat (1:800, homemade). The membranes were visualized with ECL Plus reagent (GE Healthcare) and developed onto X-ray film (Kodak).

\section{Results}

\section{Cholesterol lowering effect of GBE in hepatocytes}

To determine whether GBE modulates cholesterol levels in hepatocytes, HepG2, and SK-HEP-1 cells were cultured in medium with or without various concentrations of either GBE or lovastatin (positive control). The total cholesterol content was measured using a colorimetric assay. After $24 \mathrm{~h}$ of treatment, GBE decreased the total cholesterol content in a dosedependent manner in both HepG2 and SK-HEP-1 cells. Lovastatin $(0.5 \mu \mathrm{mol} / \mathrm{L})$ also decreased the total cholesterol content (Figure 1A, 1B). In HepG2 cells, both $0.5 \mu \mathrm{mol} / \mathrm{L}$ of lovastatin and $200 \mu \mathrm{g} / \mathrm{mL}$ of GBE demonstrated a time-dependent effect on cholesterol content. The maximum cholesterol reduction was observed at $24 \mathrm{~h}$, whereas a moderate recovery was observed after $48 \mathrm{~h}$ (Figure 1C, 1D).

\section{Inhibition of HMG-CoA reductase activity}

To test whether GBE affects the activity of HMG-CoA reductase, the rate limiting enzyme in cholesterol biosynthesis, we performed an experiment using in vitro reacted hepatic microsomes. The activity of HMG-CoA reductase was inhibited by both GBE and lovastatin. A dose of $129 \mathrm{nmol} / \mathrm{L}$ of lovastatin inhibited the HMG-CoA reductase activity by $25.2 \%$. GBE inhibited HMG-CoA reductase activity by $6.2 \%$, $16 \%$ and $71.6 \%$ at concentrations of $32.26,322.6$, and 3226 $\mu \mathrm{g} / \mathrm{mL}$, respectively (Table 1 ).

Table 1. Effect of GBE and lovastatin on HMG-CoA reductase activity in in vitro experiment. $n=3$ for each group. Mean \pm SD. ${ }^{b} P<0.05,{ }^{c} P<0.01$ vs control group using One-Way ANOVA.

\begin{tabular}{lccc}
\hline Group & Concentration & $\begin{array}{c}\text { Activity } \\
\left(10^{-5} \mu \mathrm{mol} \cdot \mathrm{min}^{-1} \cdot \mathrm{mg}^{-1}\right)\end{array}$ & $\begin{array}{c}\text { Inhibition } \\
(\%)\end{array}$ \\
\hline Control & 0 & $55 \pm 0.7$ & 0 \\
GBE & $32.26 \mu \mathrm{g} / \mathrm{mL}$ & $52 \pm 1.8^{\mathrm{b}}$ & $6.2 \pm 2.5$ \\
& $322.6 \mu \mathrm{g} / \mathrm{mL}$ & $47 \pm 1.6^{\mathrm{c}}$ & $16.0 \pm 2.5$ \\
Lovastatin & $3226 \mu \mathrm{g} / \mathrm{mL}$ & $16 \pm 4.1^{\mathrm{c}}$ & $71.6 \pm 7.1$ \\
& $129 \mathrm{nmol} / \mathrm{L}$ & $40 \pm 3.6^{\mathrm{c}}$ & $27.2 \pm 6.8$ \\
\hline
\end{tabular}

\section{Effect of GBE on cholesterol fluxes in HepG2 cells}

We determined the effect of GBE on cholesterol flux. In HepG2 cells, lovastatin induced a significant increase in cholesterol influx. In contrast, GBE inhibited cholesterol influx in a dose-dependent manner (Figure 2A). No significant alterations in cholesterol efflux were observed in HepG2 cells treated with either GBE or lovastatin (Figure 2B).

\section{Transcriptomic profiling induced by GBE in HepG2 cells}

To determine the mechanisms underlying the effect of GBE on cholesterol lowering, we performed microarray analysis. The global transcriptomic profiling of the cells treated with either GBE or lovastatin is shown with PCA plots. We identified 1264 regulated genes/ESTs, which are shown as PCA and CPP-SOM (Figure 3A, 3B, www.shbiochip.com/ research/GBE/HepG2). These results demonstrate a similar gene expression profile regulation of both GBE and lovastatin. With ontology annotations, 254 of the regulated genes were
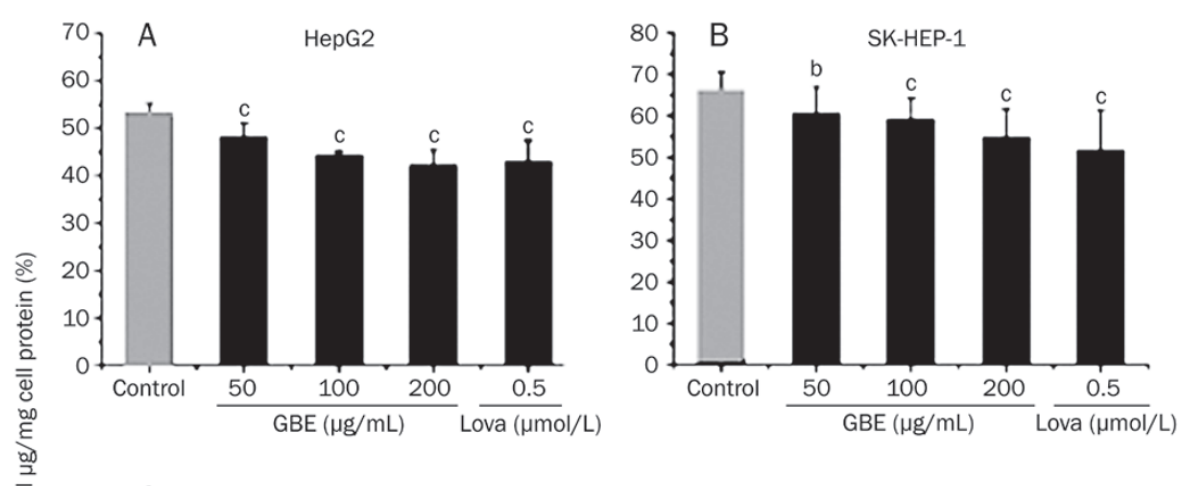

Figure 1. GBE and lovastatin decreased the total cholesterol content in cultured hepatocytes. (A, B) HepG2 and SK-HEP-1 cells were treated with $\operatorname{GBE}(50,100,200 \mu \mathrm{g} / \mathrm{mL})$ or lovastatin $(0.5 \mu \mathrm{mol} / \mathrm{L})$ for $24 \mathrm{~h}$ in MEM-2\%FBS
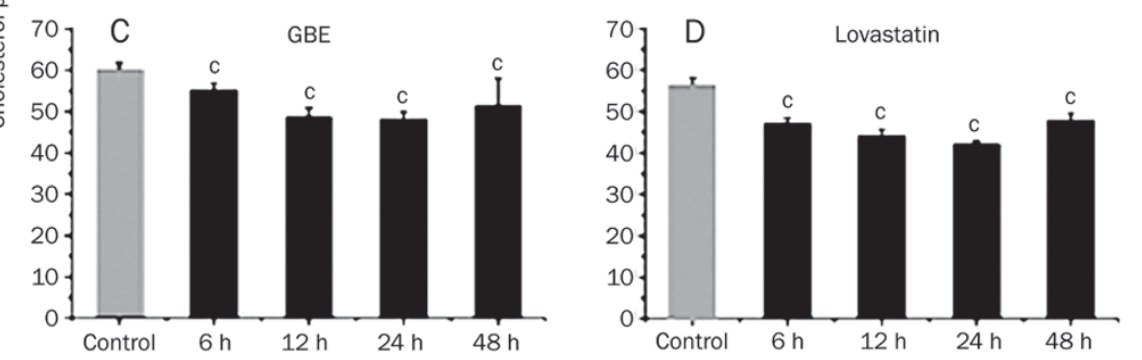
media, and the total cholesterol content was decreased in a dose-dependent manner. (C, D) GBE $(200 \mu \mathrm{g} / \mathrm{mL})$ and lovastatin $(0.5 \mu \mathrm{mol} / \mathrm{L})$ decreased the cellular total cholesterol content in a time-dependent manner $(6,12,24 \mathrm{~h})$ in MEM-2\%FBS media, while a moderate recovery was observed after $48 \mathrm{~h}$ of treatment. $n=3$ independent experiments. Mean \pm SD. ${ }^{\mathrm{b}} P<0.05$, ${ }^{c} P<0.01$ vs control group using One-way ANOVA. 

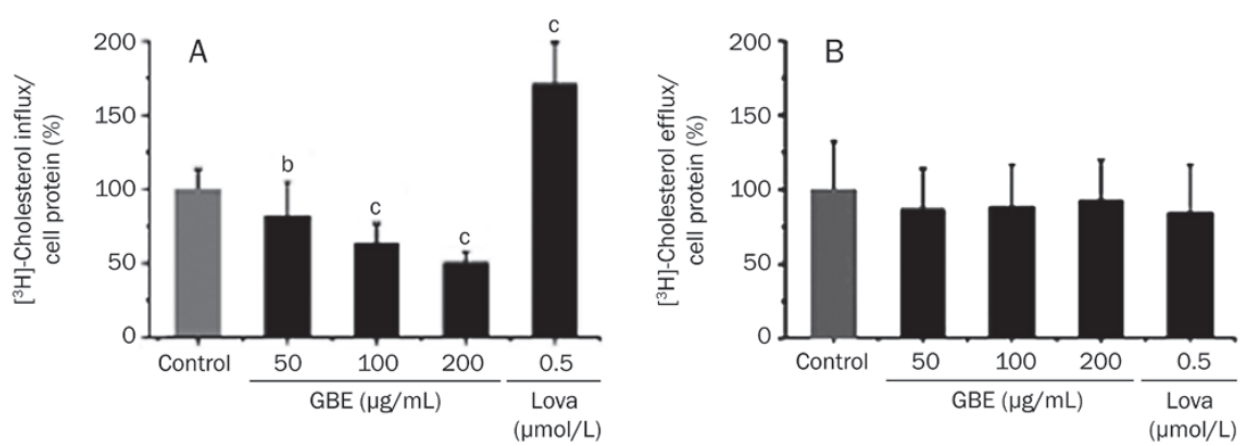

Figure 2. Effect of GBE and lovastatin on cholesterol fluxes in HepG2 cells. (A) Cholesterol influx was inhibited by GBE in a dose-dependent $(50,100$, and 200 $\mu \mathrm{g} / \mathrm{mL}$ ) manner in MEM-2\%FBS after $24 \mathrm{~h}$ of treatment, whereas it was increased by lovastatin. (B) Cholesterol efflux was not significantly altered by GBE or lovastatin in MEM-2\%FBS after $24 \mathrm{~h}$ of treatment. Mean $\pm S D$ from three independent experiments. ${ }^{b} P<0.05,{ }^{c} P<0.01$ vs the control group using One-Way ANOVA.
A

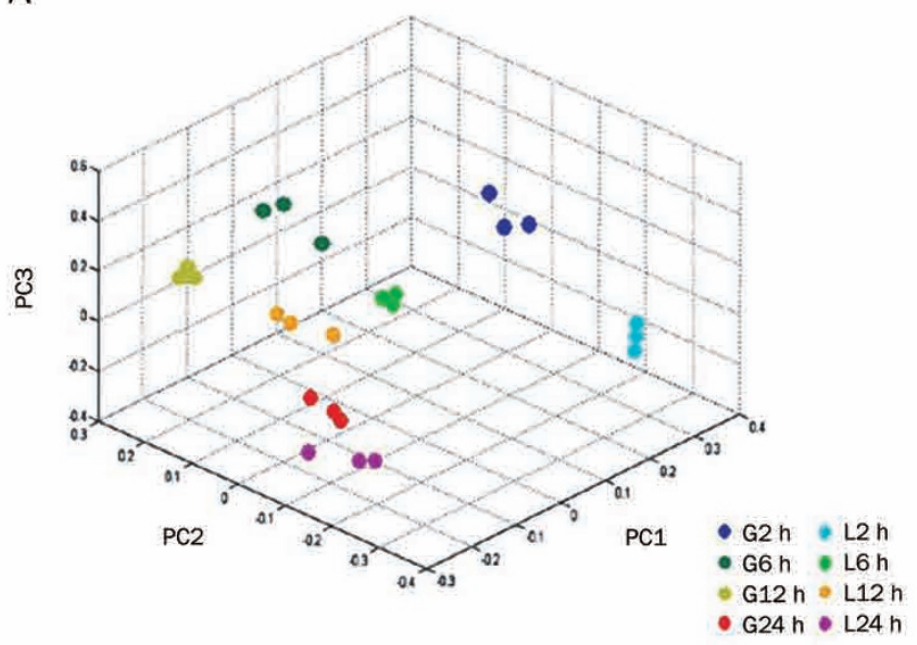

C

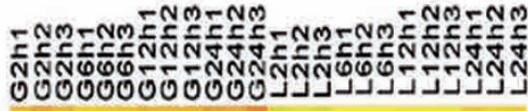

B

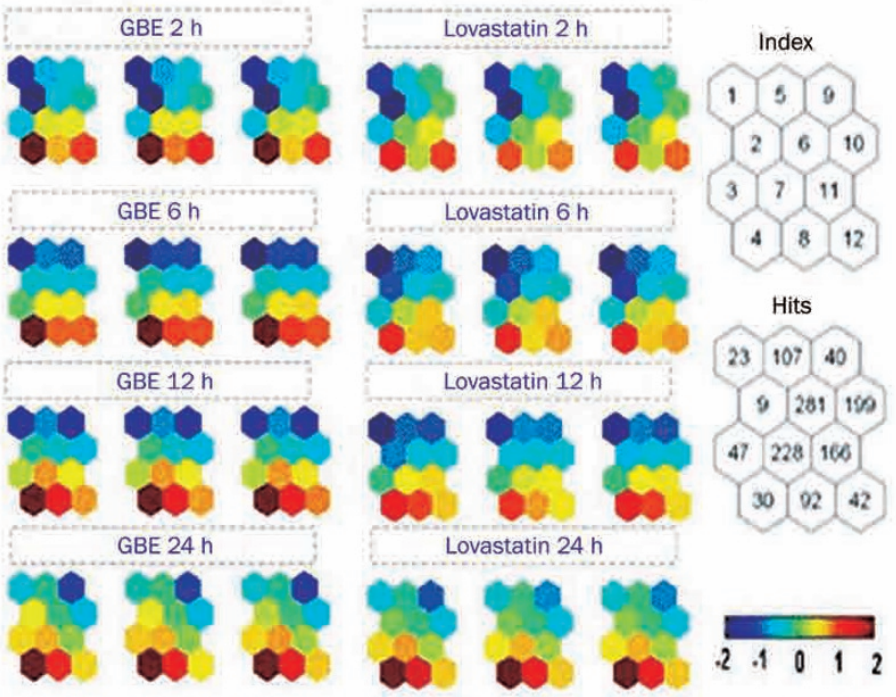

NI 001643 APOA2

AKŌ22929 HSD17B7

17I $001096 \mathrm{KCL}$

Bi-006821 КСОT2

BI 000039 APOA1

171_000859 WIGCR

BNI 006745 SCANIOL

171-004508 IDII

AK0̄25736 MIGCS1

INI 003129 SQLF

Mi 000786 CYP51A

INI 001360 DKCRT

17i_004462 FDFI1

MI 005891 ACKT2

171_002004 FDPS

AB0322261 SCD

N. 018677 ACSS2

AL 033527 OKCT2

III 002629 PGNII

Bi-003273 IIITSF2

171 002340 LSS

Mi_004265 FADS2

MI 014762 DHCR24

VII_005327 HLDH

17i 006512 SHL4

111 022977 ACSLA

17i-024090 ELVVL

171 002858 ABCD3

13i_000235 LIPA

BII 000499 CYP1A1

NII 018238 kGK.

NII 016011 HECR

III_005123 IRIHA

AK023717 PRKLB2

1NI 000271 NPCI

BC0009326 SCARP2

ㄱ! 021122 FACL2

171 019101 APOI

7. 021727 FADS3

MII 014045 LRP10

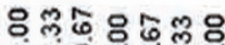

4.

Figure 3. Dynamic changes in gene expression regulated by GBE and lovastatin. (A) Principal components analysis (PCA) of the filtered 9510 gene/ ESTs from all samples. The PCA plot discriminated transcriptomic profiling of cells at different time points between GBE and lovastatin treatments. (B) Visualization of the SOM plots by CPP with the 1264 regulated genes/ESTs. Each presentation illustrates a sample specific transcription map, upregulated (red), downregulated (blue) and moderately regulated (yellow and green) genes were delineated. The color index stands for the log(2) transformed ratios. The triplicate samples were plotted individually to show the consistency of the biological replications. Index and number of genes contained in each section (hit) are indicated at the right. (C) Microarray analysis of the changes in lipid metabolism related genes that are regulated by GBE and lovastatin. Red represents upregulation, while green represents downregulation, and the color bar is indicated underneath. G represents GBE treatment, L represents lovastatin treatment. 
assigned to groups based on their biological functions, such as lipid metabolism (Figure 3C), fibrinogenesis, trafficking, and metabolism (Figure S1). Detailed information on the regulated genes is provided in the supplementary material. Real-time RT-PCR was conducted on eight genes. GAPDH was used as an internal control because it was not modulated by GBE or lovastatin based on both the microarray and the semi-quantitative RT-PCR data (data not shown). The RT-PCR results demonstrated consistency with the microarray data (Figure S2).

We further distinguished the differential regulation between GBE and lovastatin treatment of 228 of the regulated genes/ ESTs for at least one time point (Table S2). Of these 228 genes, a potential target of GBE and lovastatin could be identified and the different mechanisms of the two drugs could be derived. For example, the fibrinogen A gene (FGA) was significantly downregulated at an early time point with GBE, but not with lovastatin. Furthermore, CYP1A1 was upregulated earlier and more strongly with GBE treatment compared with lovastatin treatment. In addition, TGFBR3 was gradually upregulated by GBE but not regulated by lovastatin.

\section{Regulation of the cholesterol metabolism pathway}

Transcriptomic profiling revealed that GBE induced a significant change in the expression of genes in the cholesterol metabolic pathway. Genes involved in cholesterol biosynthesis, such as HMG-CoA reductase (HMGCR), isopentenyldiphosphate delta isomerase 1 (IDI1), sterol $O$-acyltransferase (SQLE), HMG-CoA synthase 1 (HMGCS1), farnesyl-diphosphate farnesyltransferase 1 (FDFT1), farnesyl-diphosphate synthase (FDPS) and lanosterol synthase (LSS), were consistently upregulated (Figure 3C and Figure S3). NR1H4, which encodes the transcription factor farnesoid $X$ receptor $(F X R)$, was downregulated by both GBE and lovastatin. Additionally, transcriptomic profiling revealed that GBE downregulates genes associated with cholesterol uptake, including scavenger receptor class F member 2 (SCARF2), Niemann-Pick type C1 (NPC1) and LDL receptor-related protein 10 (LRP10) (Figure 3C).

We further examined 20 cholesterol metabolism-related genes by real-time RT-PCR. We identified that the mRNA levels of HMGCR and SREBF2 (encoding sterol regulatory element-binding protein 2) were upregulated by GBE. On the other hand, the mRNA level of the SREBF chaperone (SCAP)
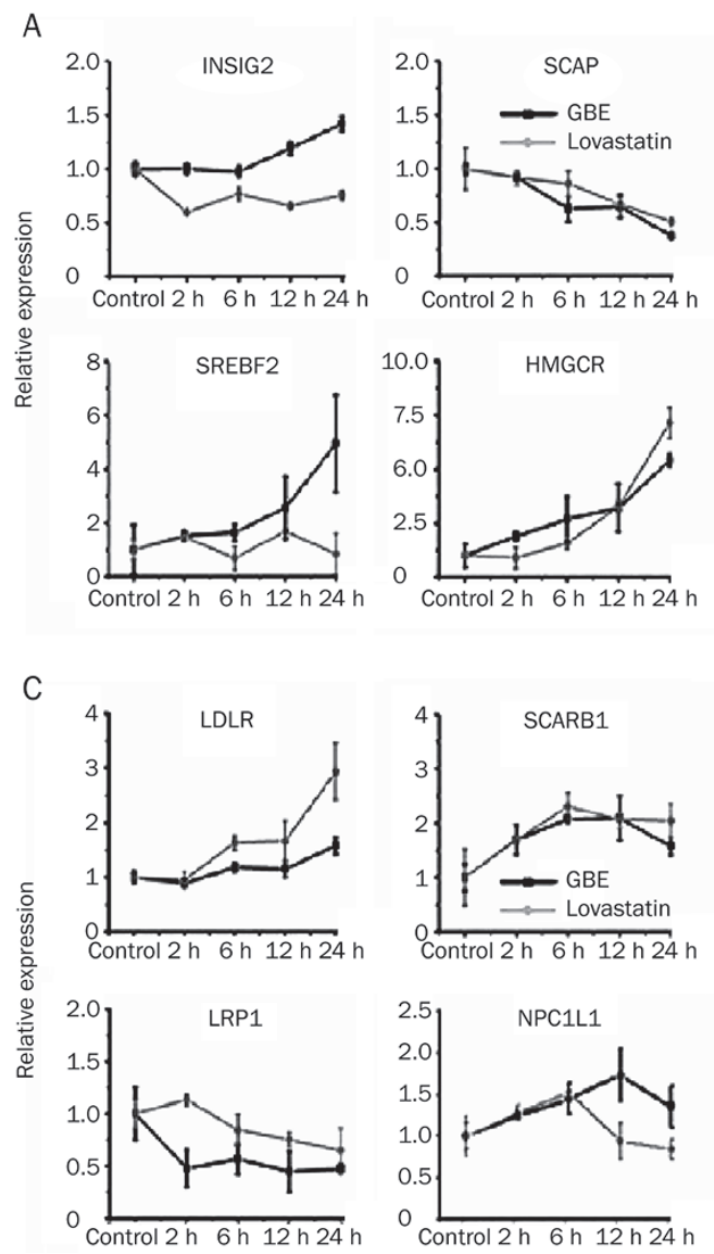

B
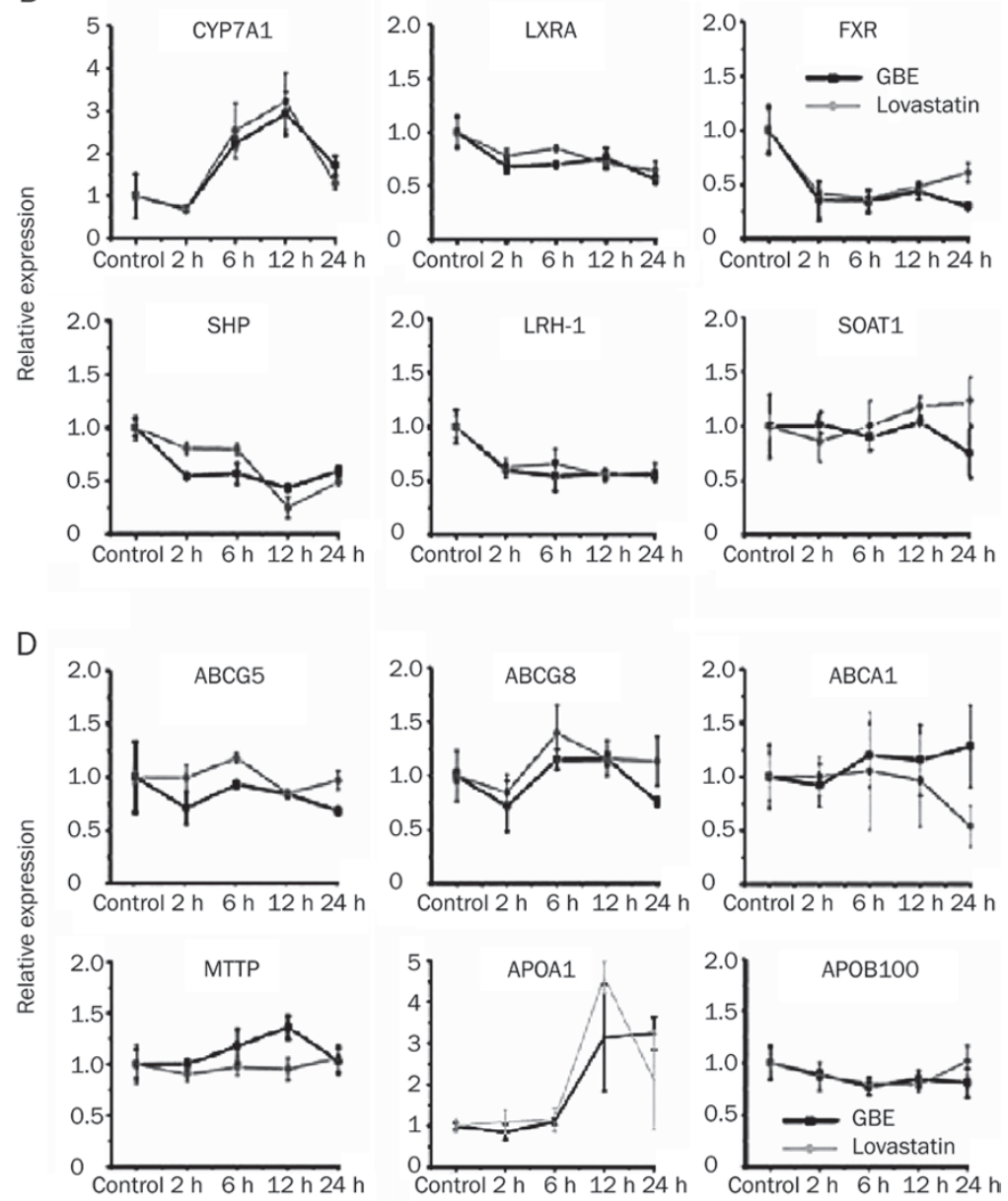
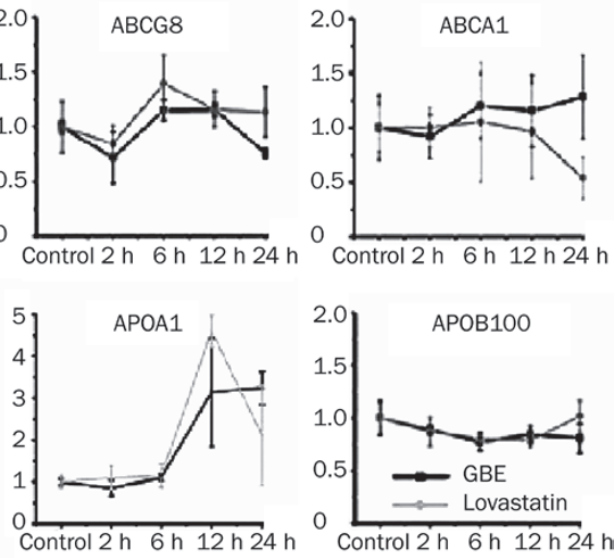

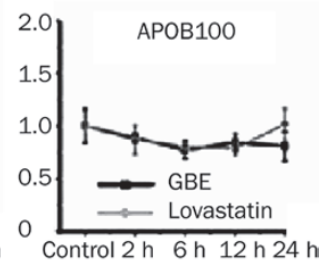

Figure 4. Examination of the cholesterol metabolism related genes with real-time PCR. GAPDH was used as an internal control. Gene expression was calculated with threshold cycles, the expression of each gene in the control group was set to 1. $n=3$. Data are presented as the relative average \pm SD. 

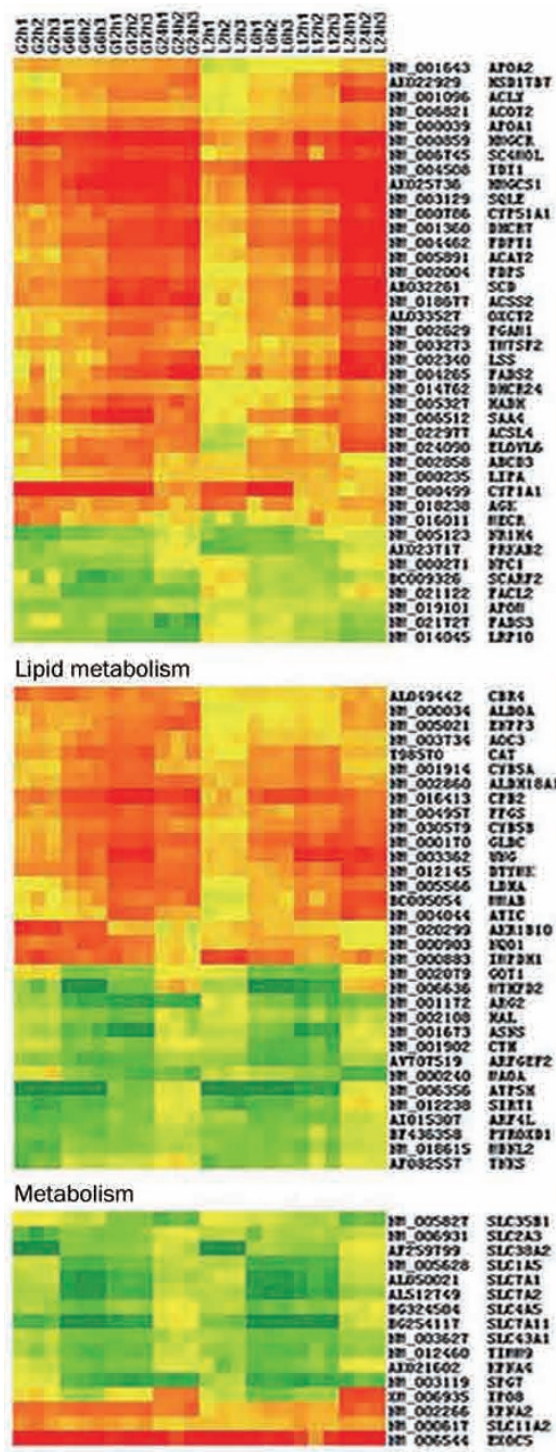

Trafficking

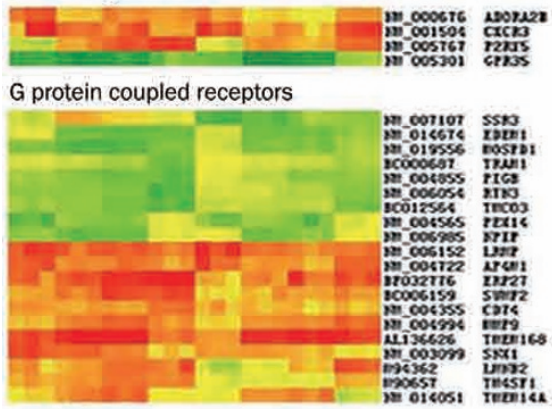

Membrane protein

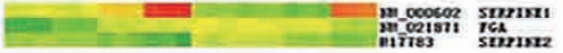

Fibrogenesis and fibrolysis

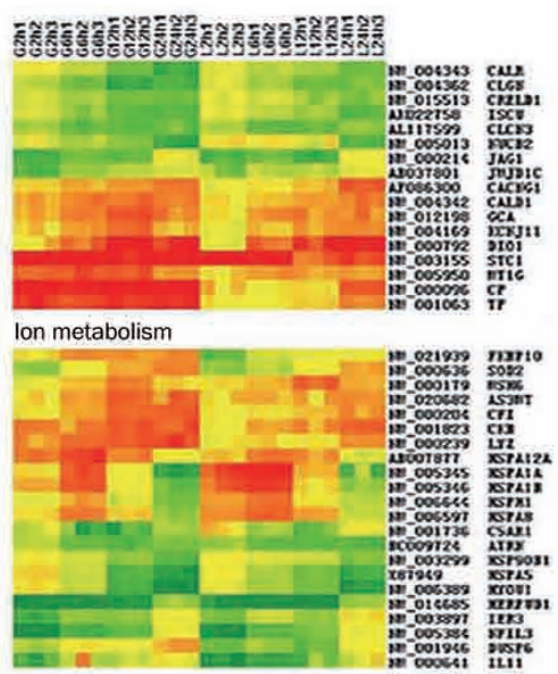

\section{Homeostasis and stress}

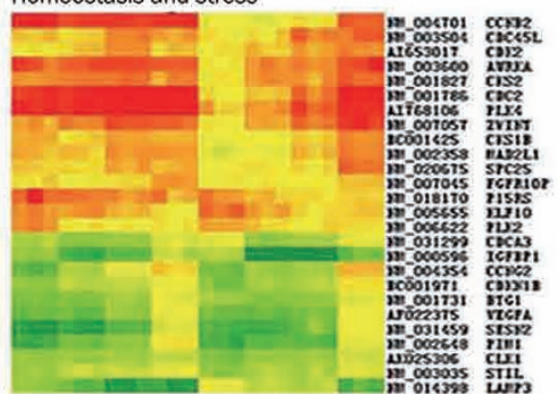

Cell proliferation

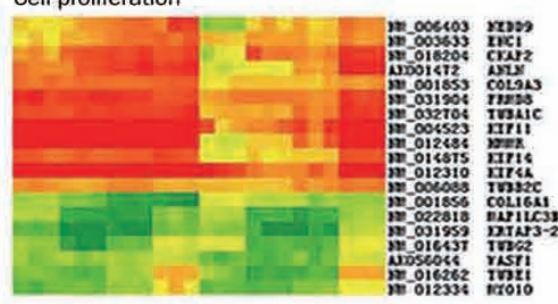

Cytoskeleton

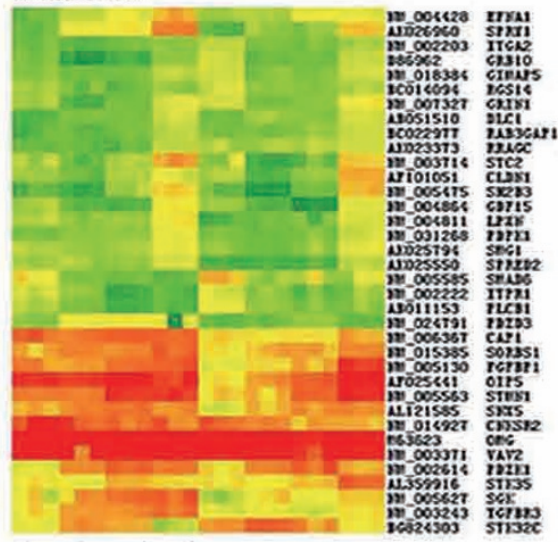

Signal transduction

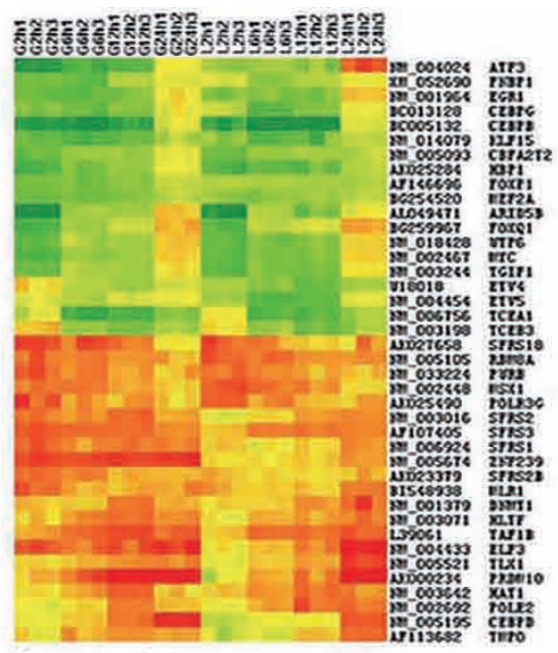

Gene transcription

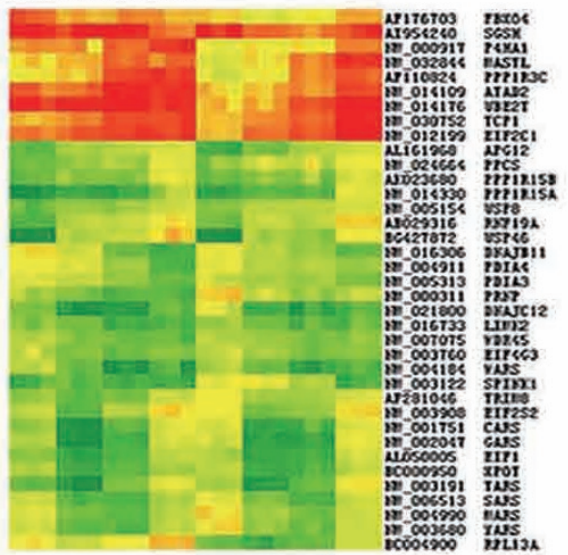

Protein expression and modification

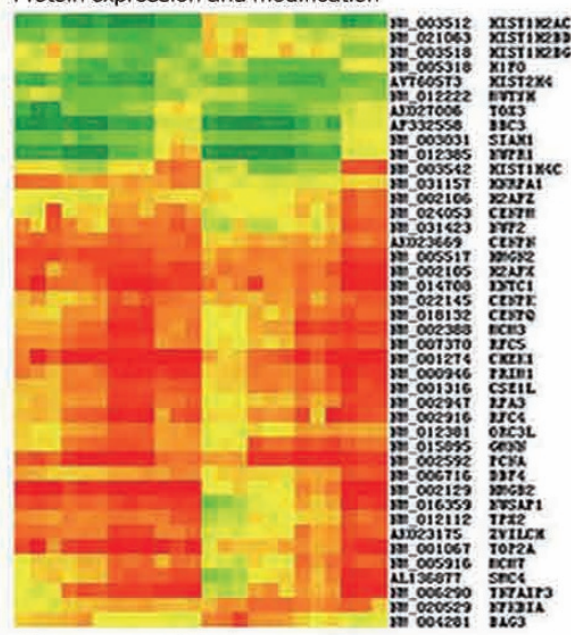

Chromosome related

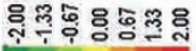

Figure S1. Functional categories of the representative genes that were regulated by GBE50 and lovastatin in HepG2 cells. Functional features of each gene were determined based on its ontology annotation and published literature. All the relevant genes are grouped by hierarchical clustering based on the expression regulation (log2ratios) across all the samples (www.shbiochip.com/research/GBE/HepG2). Log2 ratios were color coded as indicated.

was downregulated by GBE (Figure 4A). The protein level of both HMGCR and SREBF2 encoding protein SREBP2 was also increased (Figure 5). Interestingly, insulin-induced gene 2 (INSIG2) was upregulated by GBE, but downregulated by 

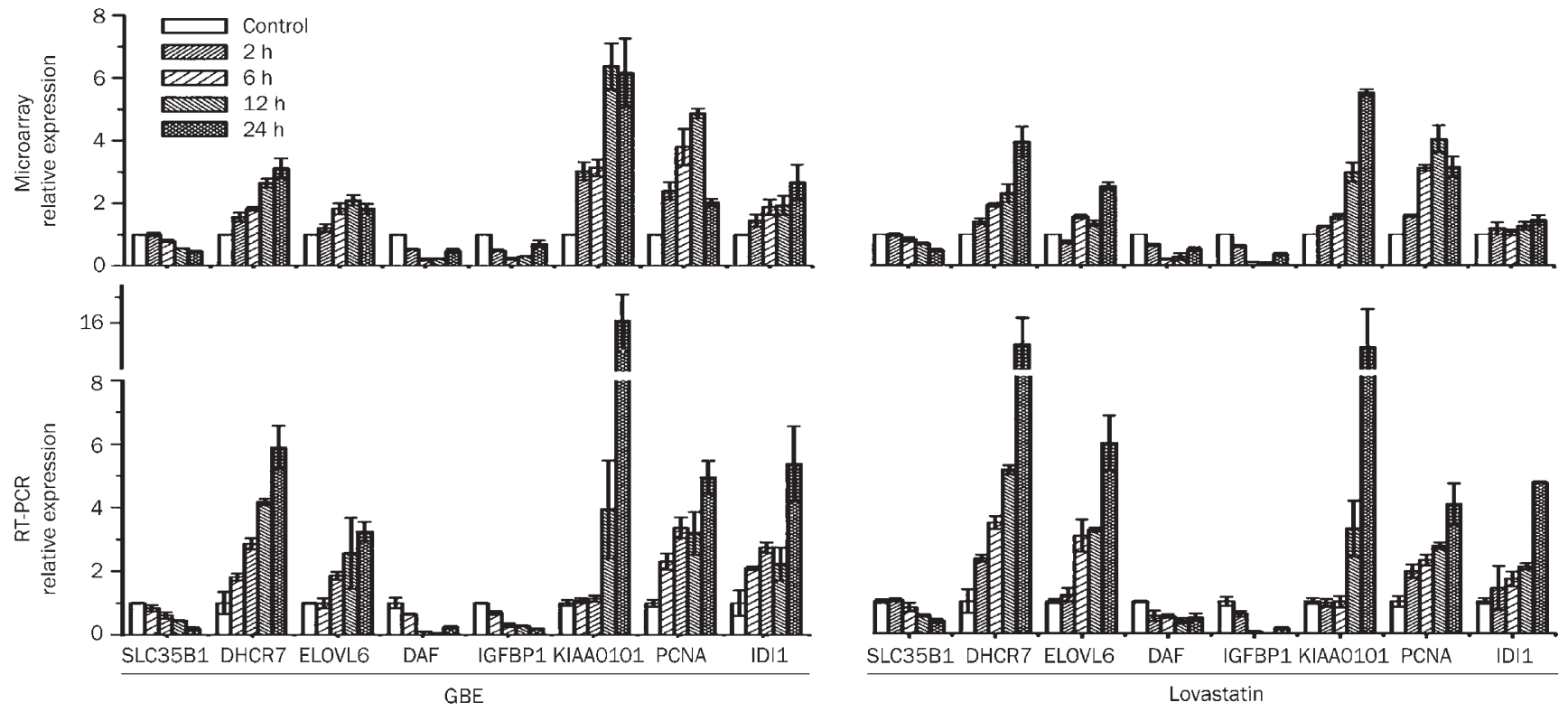

Figure S2. Validation of the microarray data with real-time RT-PCR for eight of the regulated genes. The results demonstrated a high concordance between the two methods.
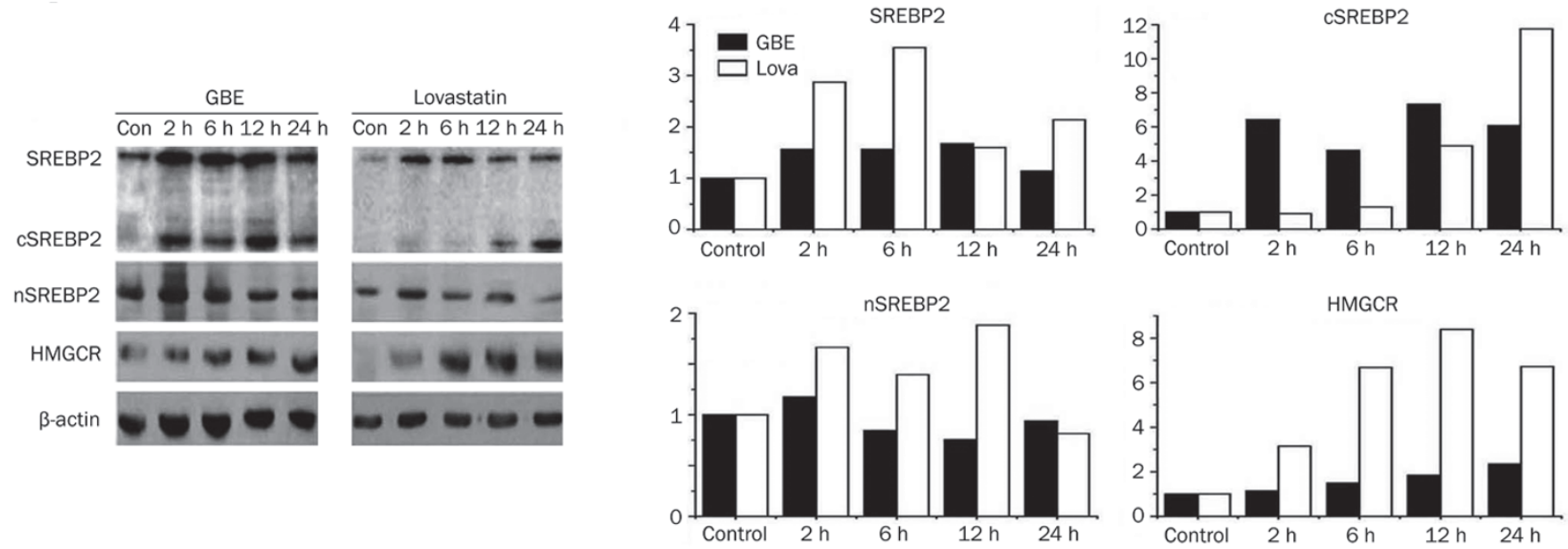

Figure 5. Western blot analysis of HMGCR and SREBP2 proteins. (A) Western blots images, (B) Signal quantitation of each band. $\beta$-actin was immunoprobed as a loading control. HMGCR was induced by both GBE50 and lovastatin, but the lovastatin had a stronger effect. The SREBP2 c-terminus was induced by GBE50 and lovastatin. The cleaved form of n-terminus nSREBP2 was upregulated by lovastatin, but not GBE50.

lovastatin.

GBE and lovastatin had similar regulatory effects on several genes involved in cholesterol catabolism. CYP7A1 (encoding cholesterol 7-alpha-hydroxylase) was upregulated by treatment with both drugs. Genes encoding the transcription factors liver $\mathrm{X}$ receptor alpha (LXRA), farnesoid $\mathrm{X}$ receptor (FXR), orphan nuclear receptor $(S H P)$, and liver receptor homolog 1 (LRH-1) were all downregulated by GBE and lovastatin. Sterol O-acyltransferase (SOAT1) was not significantly regulated by treatment with either GBE or lovastatin (Figure 4B).

Genes involved in cholesterol influx, such as the LDL receptor $(L D L R)$, the scavenger receptor class $\mathrm{B}$ member 1 (SCARB1) and Niemann-Pick C1-like protein 1 (NPC1L1), were all upregulated by GBE and lovastatin. However, LDL-related protein 1 (LRP1) was downregulated. Lovastatin upregulated $L D L R$, but downregulated LRP1 expression to a greater extent than GBE (Figure 4C). Cholesterol efflux-related genes, such as transporter genes, ATP-binding cassette 1 (ABCA1), ATPbinding cassette 5 (ABCG5), ATP-binding cassette 8 (ABCG8), microsomal triglyceride transfer protein $(M T T P)$ and apolipoprotein B 100 (APOB100), were not significantly regulated. However, the cholesterol efflux gene apolipoprotein A-I (APOA1) was upregulated by both GBE and lovastatin (Figure 3D, Figure 6). 
GBE50

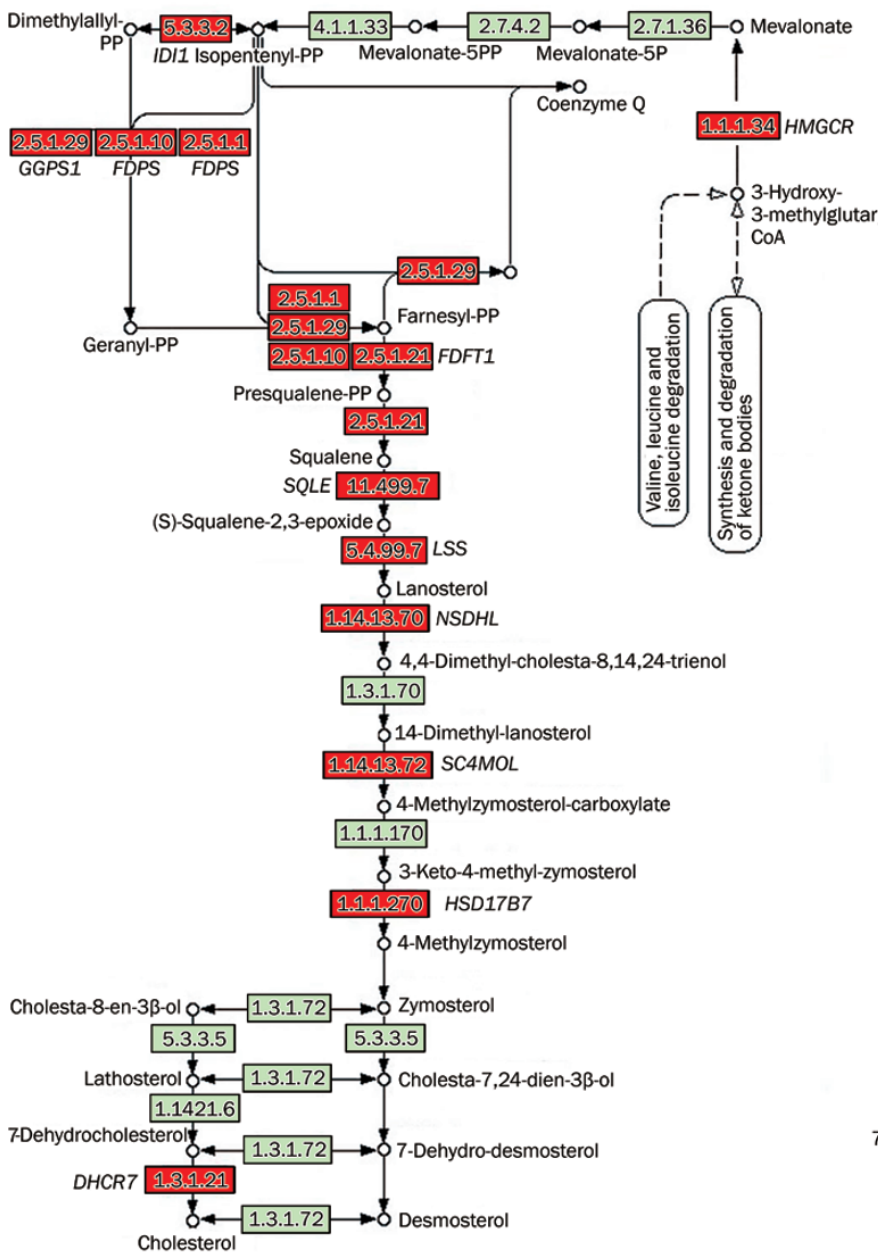

Lovastatin

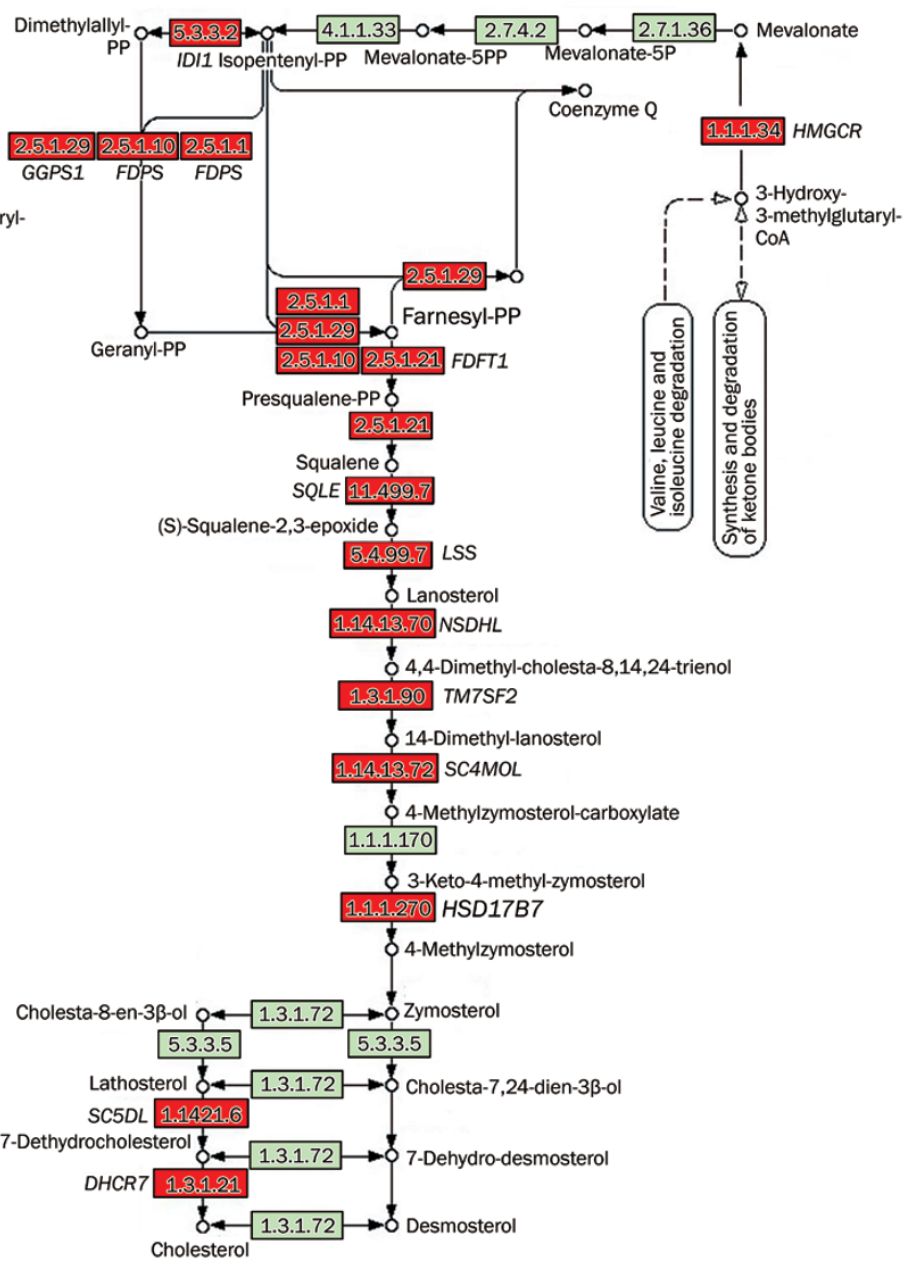

Figure S3. Genes involved in the cholesterol biosynthesis pathway were upregulated by GBE50 and/or lovastatin. Genes in red were observed to be over expressed, while the genes in light green indicate no significant changes.

\section{Discussion}

In the present study, the cholesterol lowering effect of GBE was demonstrated in cultured hepatocytes. We used lovastatin as a positive control because it functions as an HMGCoA reductase inhibitor. Here, we demonstrate that GBE also inhibits the activity of HMG-CoA reductase in an in vitro enzymatic activity assay using hepatic microsomes. Based on the claim that flavonoids possess a blood cholesterol levellowering effect by inhibiting HMG-CoA reductase activity ${ }^{[21]}$ and the major component of GBE is flavonoids $(\sim 24 \%)$, it is likely that the flavonoids in GBE contribute to its cholesterollowering effect. However, the exact active components in GBE that are involved in lowering cellular cholesterol are not precisely known.

Based on the pleiotropic effects of GBE, we used transcriptomic profiling analysis to allow us to assess multiple genes simultaneously. We propose that this approach is essential for understanding the complex mechanisms of phytomedicines. Previous studies have widely used transcriptomic strategies to explore drug regulation networks ${ }^{[22,23]}$. In the current study, transcriptomic profiling revealed that GBE induces significant gene expression changes in cultured hepatocytes. These data broadened our understanding of the molecular mechanisms by which GBE exerts its pleiotropic effects. In particular, our study focused on defining the molecular mechanisms by which GBE treatment modulates the genes involved in cholesterol metabolism.

Cholesterogenic genes are predominantly regulated through a feedback mechanism involving the cellular cholesterol pool. In this study, we show that GBE and lovastatin both lower cellular cholesterol by inducing an adaptive response in gene expression changes. Most members of the cholesterol biosynthesis pathway were increased. Additionally, we observed upregulation of $S R E B F 2$, a ubiquitously expressed transcription factor that controls cholesterol homeostasis by stimulating the transcription of sterol-regulated genes ${ }^{[24]}$. Thus, the observed upregulation of SREBF2 and cholesterogenic genes suggests that GBE lowers cholesterol through an adaptive response. In addition INSIG2, an endoplasmic reticulum protein that binds SCAP and blocks the export of SREBPs to the 
Table S2. List of genes with different regulations with GBE and lovastatin.

\begin{tabular}{|c|c|c|c|c|c|c|c|}
\hline Genbank & Symbol & Genbank & Symbol & Genbank & Symbol & Genbank & Symbol \\
\hline Al335447 & ABCB6 & BC008360 & FAM113B & D29954 & NCAPD3 & AF113682 & TMPO \\
\hline NM_013375 & ABT1 & AB046794 & FAM29A & NM_005381 & $\mathrm{NCL}$ & NM_004237 & TRIP13 \\
\hline NM_005891 & ACAT2 & NM_012300 & FBXW11 & BG612832 & NEDD1 & NM_015516 & TSKU \\
\hline NM_001096 & $\mathrm{ACLY}$ & NM_004462 & FDFT1 & AB037925 & NFKBIZ & NM_004615 & TSPAN7 \\
\hline NM_001096 & ACLY & R82935 & FDPS & NM_000271 & NPC1 & NM_032704 & TUBA1C \\
\hline NM_022977 & ACSL4 & NM_002004 & FDPS & NM_005013 & NUCB2 & NM_006088 & TUBB2C \\
\hline BC006121 & AIFM2 & NM_021871 & FGA & NM_016359 & NUSAP1 & NM_014176 & UBE2T \\
\hline NM_020299 & AKR1B10 & NM_005130 & FGFBP1 & NM_002539 & ODC1 & NM_019116 & UBFD1 \\
\hline NM_002860 & ALDH18A1 & NM_004497 & FOXA3 & AF025441 & OIP5 & NM_003362 & UNG \\
\hline AK026685 & AMMECR1L & AF146696 & FOXP1 & NM_002568 & PABPC1 & NM_003368 & USP1 \\
\hline NM_001145 & ANG & NM_031904 & FRMD8 & NM_000919 & PAM & AK023675 & UTRN \\
\hline U79297 & ANKRD46 & ВC006997 & G3BP1 & NM_001618 & PARP1 & AK022888 & WDFY1 \\
\hline AK001472 & ANLN & NM_000512 & GALNS & U80735 & PAXIP1 & NM_007086 & WDHD1 \\
\hline NM_001153 & ANXA4 & NM_000821 & GGCX & NM_002592 & PCNA & D26488 & WDR43 \\
\hline NM_001641 & APEX1 & NM_005271 & GLUD1 & NM_004911 & PDIA4 & ВC002329 & WIZ \\
\hline NM_001643 & APOA2 & NM_006578 & GNB5 & BI761657 & PIM3 & NM_003400 & XP01 \\
\hline NM_001643 & APOA2 & NM_002106 & $\mathrm{H} 2 \mathrm{AFZ}$ & Al768106 & PLK4 & NM_021994 & ZNF277P \\
\hline NM_019101 & APOM & NM_005327 & $\mathrm{HADH}$ & NM_006903 & PPA2 & AF151023 & ZNF581 \\
\hline NM_004044 & ATIC & NM_003512 & HIST1H2AC & NM_004703 & RABEP1 & AK023175 & ZWILCH \\
\hline NM_005504 & BCAT1 & NM_002129 & HMGB2 & NM_006479 & RAD51AP1 & NM_007057 & ZWINT \\
\hline AB067490 & C14orf106 & NM_000859 & HMGCR & NM_002880 & RAF1 & AB012922 & \\
\hline NM_031210 & C14orf156 & XM_048933 & HMGCS1 & ВС018163 & RALB & AB032261 & \\
\hline NM_001735 & C5 & NM_005517 & HMGN2 & NM_007370 & RFC5 & AF076675 & \\
\hline BG216972 & C6orf182 & NM_012484 & HMMR & NM_012249 & $\mathrm{RHOQ}$ & AF196969 & \\
\hline AL133014 & C7orf20 & NM_020995 & HPR & NM_024539 & RNF128 & AF305057 & \\
\hline AF086300 & CACNG1 & NM_003299 & HSP90B1 & NM_002947 & RPA3 & AF382013 & \\
\hline NM_004343 & CALR & X87949 & HSPA5 & NM_005980 & S100P & Al015307 & \\
\hline AL122079 & CCDC14 & NM_002157 & HSPE1 & NM_004757 & SCYE1 & Al128239 & \\
\hline NM_004701 & CCNB2 & NM_006389 & HYOU1 & NM_000602 & SERPINE1 & Al581732 & \\
\hline NM_004354 & CCNG2 & BC002640 & IFT20 & NM_003016 & SFRS2 & АK023379 & \\
\hline NM_001786 & CDC2 & NM_000883 & IMPDH1 & AF107405 & SFRS3 & AK025736 & \\
\hline NM_005195 & CEBPD & NM_014869 & IQSEC1 & NM_000617 & SLC11A2 & AL035689 & \\
\hline NM_018132 & CENPQ & AL049321 & IRAK1BP1 & NM_006841 & SLC38A3 & AL110194 & \\
\hline NM_000204 & $\mathrm{CFI}$ & NM_033666 & ITGB1 & NM_003090 & SNRPA1 & AL137144 & \\
\hline BC001425 & CKS1B & NM_002217 & ITIH3 & AL121585 & SNX5 & AV721426 & \\
\hline NM_001856 & COL16A1 & BG035179 & KCTD11 & NM_000454 & SOD1 & AV743808 & \\
\hline AK024070 & CTPS2 & AB006624 & KIAA0286 & NM_000636 & SOD2 & BC000222 & \\
\hline NM_001908 & CTSB & AL390128 & KIAA1530 & NM_003105 & SORL1 & BC001209 & \\
\hline NM_030579 & CYB5B & AB051499 & KIAA1712 & NM_003105 & SORL1 & BC013135 & \\
\hline NM_000499 & CYP1A1 & NM_014875 & KIF14 & NM_020675 & SPC25 & BF508697 & \\
\hline NM_018122 & DARS2 & NM_012310 & KIF4A & NM_003122 & SPINK1 & BF570946 & \\
\hline NM_006716 & DBF4 & NM_002266 & KPNA2 & AK025550 & SPRED2 & D63874 & \\
\hline NM_014762 & DHCR24 & NM_002296 & LBR & NM_003129 & SQLE & D80000 & \\
\hline ВС007339 & DHRS2 & NM_005566 & LDHA & AL359916 & STK35 & NM_001101 & \\
\hline NM_016306 & DNAJB11 & NM_000235 & LIPA & NM_003600 & STK6 & NM_001731 & \\
\hline U97105 & DPYSL2 & M94362 & LMNB2 & AF131808 & STX7 & NM_002950 & \\
\hline NM_012145 & DTYMK & U28831 & LOC400986 & AF058954 & SUCLG2 & NM_004169 & \\
\hline NM_004428 & EFNA1 & NM_002358 & MAD2L1 & NM_030752 & TCP1 & NM_005899 & \\
\hline NM_012199 & ElF2C1 & NM_032844 & MASTL & NM_003217 & TEGT & NM_006821 & \\
\hline NM_003750 & EIF3A & NM_002388 & МСMЗ & NM_003243 & TGFBR3 & NM_007021 & \\
\hline NM_004433 & ELF3 & NM_002388 & МСM3 & NM_005521 & TLX1 & NM_007363 & \\
\hline NM_003633 & ENC1 & NM_016011 & MECR & M90657 & TM4SF1 & NM_012112 & \\
\hline NM_014805 & EPM2AIP1 & NM_004994 & MMP9 & NM_003963 & TM4SF5 & NM_016126 & \\
\hline NM_001981 & EPS15 & NM_005591 & MRE11A & NM_003273 & TM7SF2 & NM_031157 & \\
\hline NM_001982 & ERBB3 & NM_000251 & $\mathrm{MSH} 2$ & AL136626 & TMEM168 & R89610 & \\
\hline AF086028 & ERBB3 & NM_002455 & MTX1 & NM_004872 & TMEM59 & T49106 & \\
\hline AL512760 & FADS1 & NM_014865 & NCAPD2 & L19183 & TMEM97 & XM_051499 & \\
\hline
\end{tabular}



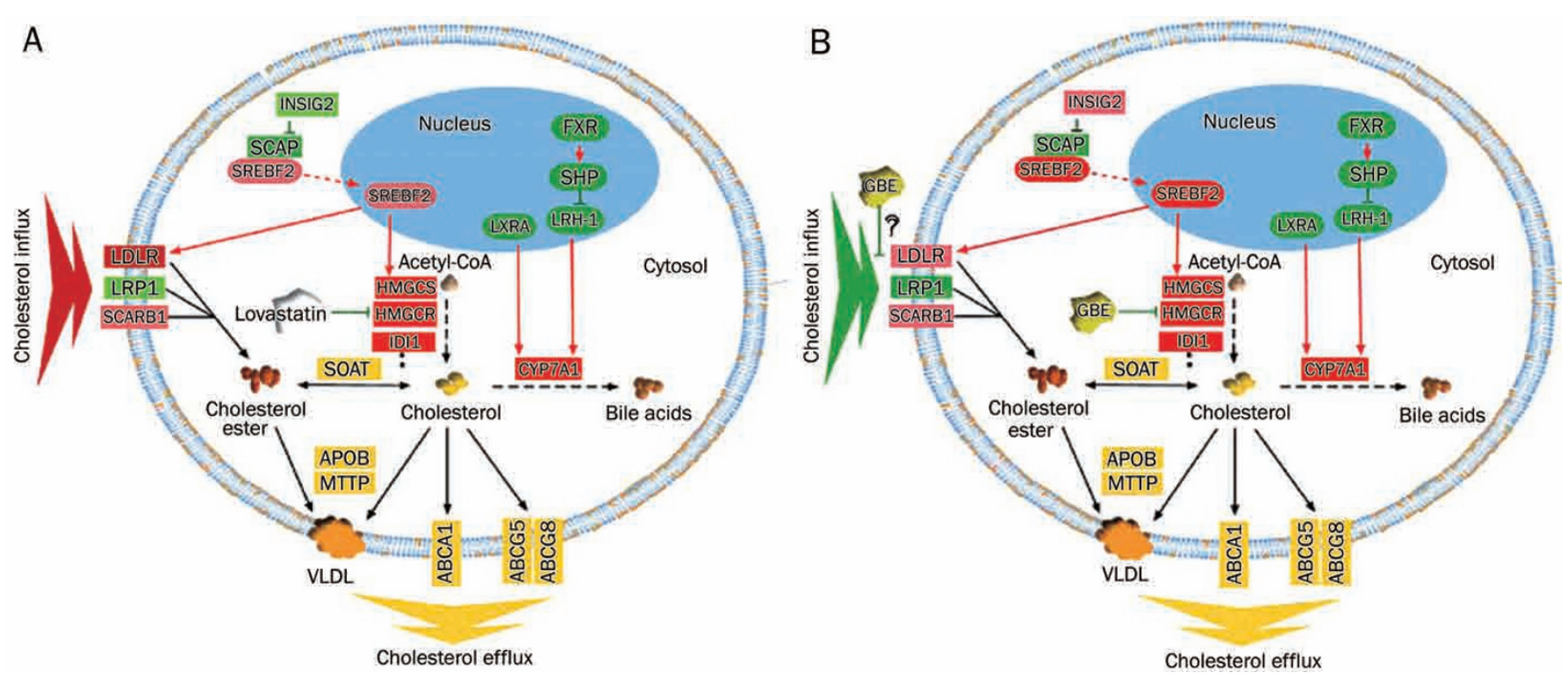

Figure 6. Ideogram illustration of the gene regulation networks underlying the cholesterol-lowering effect of GBE and lovastatin treatment in HepG2 cells. (A) GBE treatment. (B) Lovastatin treatment. The genes in green were down-regulated, while the genes in red were over-expressed, the yellow color represents genes that were not significantly changed, the red arrows indicated stimulation, the green line with block represents negative regulation. The following theme is proposed: lovastatin lowers cellular cholesterol content by inhibiting de novo biosynthesis by modulating the expression of the rate limiting enzyme, HMGCR, and inducing adaptive responses, such as the over expression of genes involved in cholesterol endogenous biosynthesis and cholesterol influx, and the down-regulation of genes related to cholesterol catabolism into bile acids, which are required for the maintenance of the homeostasis of cellular cholesterol. With respect to molecular mechanisms downstream of GBE treatment, in addition to inhibiting HMGCR, cholesterol influx was also inhibited and related gene expression changes were demonstrated.

Golgi ${ }^{[25]}$, was differentially regulated by GBE and lovastatin. These data suggest that GBE and lovastatin possess differential mechanisms for lowering cholesterol.

Cholesterol 7-alpha-hydroxylase (CYP7A1) is the ratelimiting enzyme that converts cholesterol to bile acids. The oxysterol receptor, liver $\mathrm{X}$ receptor alpha (LXRA), is the dominant regulator of CYP7A1 transcription ${ }^{[26]}$. The bile acid receptor, FXR, is activated by bile acids and subsequently represses CYP7A1 expression through a regulatory cascade involving SHP and LRH-1 ${ }^{[27]}$. In this study, LXRA, FXR, SHP, and LRH-1 were consistently downregulated by both GBE and lovastatin. Interestingly, CYP7A1 was upregulated by both cholesterollowering agents. Although CYP7A1 was upregulated, we propose that the catabolism of cholesterol to bile acids might be diminished because both the bile acid biosensor, FXR, and the dominant regulator were downregulated.

As a feedback response to the cellular cholesterol-lowering effects, lovastatin induced the overexpression of $L D L R$ and $S C A R B I$. LDLR, the LDL receptor, is involved in receptormediated endocytosis of LDL and is regulated by SREBP2 $2^{[28]}$. SCARBI (Scavenger receptor class B type I) is a high-density lipoprotein (HDL) receptor in the liver and is involved in the selective uptake of cholesteryl ester from HDL that is involved in the reverse cholesterol transport $(\mathrm{RCT})^{[29]}$. Thus, the overexpression of $L D L R$ and SCARBI could facilitate cholesterol uptake from the medium to maintain the homeostasis of the cellular cholesterol pool. However, we found that GBE inhibits the uptake of cholesterol from the medium. This result is consistent with a previous study by Qiu et al, in which GBE inhibited the hyperpermeability of endothelial cells to $\left.{ }^{[25} \mathrm{I}\right]-$ labeled oxLDL ${ }^{[30]}$. The mild upregulation of LDLR and the strong downregulation of LRP1 and LRP10 indicate that GBE is a cholesterol uptake inhibitor, although the exact mechanisms by which GBE inhibits cholesterol uptake were not identified.

The liver is largely responsible for maintaining cholesterol homeostasis. In the present study, we find that GBE inhibits cholesterol influx in HepG2 cells. These data imply that cholesterol clearance from the blood into the liver might be restrained. Although the cellular global HMG-CoA reductase activity in cells was not pursued in this study, the in vitro inhibition of HMG-CoA reductase activity suggests an attenuation of endogenous cholesterol biosynthesis. This was in agreement with our previous findings that GBE mildly inhibits the elevation of blood cholesterol levels and liver lipid accumulation induced by high-fat diet in rats ${ }^{[31]}$.

In conclusion, both GBE and lovastatin lowered the cholesterol content in cultured hepatocytes. GBE exhibited dual effects on both HMG-CoA reductase activity and cholesterol influx inhibition. The proposed similar and unique mechanisms of cholesterol lowering by GBE and lovastatin are summarized in Figure 6. Further investigation of the genes regulated by GBE is of particular importance both for understanding the unique mechanisms by which GBE regulates cholesterol metabolism and for the clinical application of GBE. 


\section{Supplementary material}

Transcriptome regulations with GBE50 and lovastatin in HepG2 cells

Among the regulated genes with ontology annotations, 254 were assigned into groups based on their biological functions (Figure S1).

\section{Lipid metabolism pathways were affected by both drugs}

Most members of the cholesterol biosynthesis pathway were upregulated in both treatment groups, including the rate limiting enzyme, 3-hydroxy-3-methylglutaryl-coenzyme A reductase (HMGCR), isopentenyl-diphosphate delta isomerase 1 (IDIl), squalene epoxidase (SQLE), 3-hydroxy-3-methylglutaryl-coenzyme A synthase 1 (HMGCS1), farnesyl-diphosphate farnesyltransferase 1 (FDFT1), farnesyl-diphosphate synthase (FDPS), lanosterol synthase (LSS), etc. Genes involved in cholesterol uptake, such as the scavenger receptor class F member (SCARF2) and Niemann-Pick disease-type C1 (NPC1) were downregulated in both treatment groups. The cellular cholesterol content sensing transcription factor, farnesoid $\mathrm{X}$ receptor (FXR) (NR1H4), was observed to be down regulated. The genes encoding the fatty acid metabolism enzymes were also significantly regulated. Acyl-CoA synthetase (ACSS2), stearoyl-CoA desaturase (SCD), hydroxyacylcoenzyme A dehydrogenase (HADH), fatty acid desaturase 2 (FADS2) and 3-oxoacid CoA transferase 2 (OXCT2) were upregulated in both treatment groups. However, fatty-acid-coenzyme A ligase (FACL2), fatty acid desaturase 3 (FADS3), as well as low density lipoprotein receptor-related protein 10 (LRP10), were more strongly downregulated by GBE50 than lovastatin.

\section{Regulations of transporters with two drugs}

Downregulation of the solute carrier proteins (SLC1A5, SLC2A3, SLC4A5, SLC7A1, SLC7A2, SLC7A11, SLC35B1, SLC38A2, $S L C 43 A 1)$, and the translocase of inner mitochondrial membrane 9 (TIMM9) revealed that cellular substance intracellular trafficking was inhibited by the both drugs. Additionally, our microarray analysis revealed that the exocyst complex component 5 (EXOC5), which is essential for post-Golgi traffic, was upregulated.

\section{Regulation of energy metabolism related genes}

The acute repression of mitochondrial $\mathrm{H}^{+}$transporting ATP synthase subunit $(A T P 5 H)$ was detected as early response to the treatment with both GBE and lovastatin; however, the expression levels were recovered to a normal level when treated for $24 \mathrm{~h}$, suggesting that energy metabolism was inhibited at an early stage when treated with either drug, but the effect only lasted for a short period. Similarly, carbohydrate metabolism-associated genes, including lactate dehydrogenase A ( $L D H A)$, aldehyde dehydrogenase member (ALDH18A1), nucleic acid metabolism related uracilDNA glycosylase (UNG), inosine monophosphate dehydrogenase (IMPDH1), etc, were upregulated. Downregulation of glutamicoxaloacetic transaminase (GOT1), methylenetetrahydrofolate dehydrogenase 2 (MTHFD2), arginase (AARG2) suggested that these drugs also inhibited amino acid metabolism. The downregulation of monoamine oxidase $\mathrm{A}(M A O A)$ is associated with a neurotransmitter degradation reduction. The early upregulation of carbonyl reductase $4(C B R 4)$, aldolase A $(A L D O A)$, aldose reductase $(A K R 1 B 10)$ and vascular adhesion protein 1 (amine oxidase, copper containing 3) (AOC3) by only GBE50 suggests that these genes are not regulated by lovastatin.
Cell signaling and communication gene expression regulations

The expression of cell-cell communication and signaling genes, including oligodendrocyte myelin glycoprotein (OMG) and Vav 2 oncogene ( $V A V 2)$, were upregulated by both drugs at an early time point and the effects lasted at least $24 \mathrm{~h}$. Serum/glucocorticoid regulated kinase (SGK) and transforming growth factor, beta receptor III (TGFBR3), fibroblast growth factor binding protein 1 (FGFBP1), and adenylate cyclase-associated protein 1 (CAP1) were upregulated with GBE50 treatment, but were either not regulated or regulated at a late time point by lovastatin treatment. Expression of the PDZ domain containing protein coding gene (PDZD3) was down regulated at earliest time point in both treatment groups, and was observed to rapidly recover to normal levels in the GBE50 treatment group, but remained repressed with lovastatin treatment. It is important to point out that the iron metabolism members, ceruloplasmin (ferroxidase) $(C P)$ and transferrin $(T F)$, were both rapidly upregulated by GBE50, but only slightly regulated at $24 \mathrm{~h}$ with lovastatin, and the downregulation of a calcium binding protein, nucleobindin 2 (NUCB2), occurred later with lovastatin than with GBE.

\section{Protein translation and modification members}

The stress response heat shock proteins (HSPA1A, -A8, -H1) were upregulated with lovastatin treatment earlier than with GBE50, and FK506 binding protein 10 (FKBP10) and dual specificity phosphatase 6 (DUSP6) were both downregulated by lovastatin at the earliest time point, but are neither up- nor downregulated by GBE50 treatment. The finding that the plasminogen activator inhibitor member 1 (SERPINE1) was upregulated, the member 2 (SERPINE2) was down regulated in both groups, and fibrinogen $\mathrm{A}$ (FGA) was repressed by GBE50, but not lovastatin at the early time point, all indicate that fibrinolysis is regulated by these two drugs.

\section{General transcription regulators}

Regulation of most transcription and protein expression/modification factors were similar between the two groups, except for the zinc finger protein (ZNF239), F-box protein 4 (FBXO4), proline 4-hydroxylase (P4HA1) and a member of the ubiquitinconjugating enzyme (UBE2T), which were upregulated, and a serine peptidase inhibitor (SPINK1), which was downregulated earlier in the GBE50 treatment group, and the ribosomal protein L13a (RPL13A) was repressed in the lovastatin group only.

\section{Chromosome structure protein genes}

Chromosome histone coding genes were downregulated in both groups. HIST1H2AC, HIST1H2BD, HIST1H2BG were downregulated earlier in the GBE50 group than with lovastatin. Highmobility group box 2 (HMGB2), nucleolar and spindle associated protein (NUSAP1), microtubule-associated protein (TPX2), kinetochore associated protein (ZWILCH), topoisomerase (TOP2) and tumor necrosis factor alpha-induced protein 3 (TNFAIP3) were all upregulated earlier, while ribonucleoprotein A1 (HNRPA1) was upregulated only with GBE50, compared to lovastatin.

\section{Membrane proteins}

The signal sequence receptor gamma (SSR3) was down- 
regulated with lovastatin at an early time point, while GBE50 had no effect on its regulation. Transmembrane 4 superfamily member 1 (TM4SF1) and lamin B2 (LMNB2) were upregulated with GBE50 earlier than lovastatin, whereas MOSPD1, PIGB, RTN3, and TMCO3 had earlier repression with GBE50 treatment than with lovastatin.

\section{Cell proliferation members}

Cell proliferation was enhanced with GBE50 compared to lovastatin. Cell proliferation promoting genes, including CCNB2, CDC2, AURKA, PLK4, MAD2L1, were upregulated earlier with GBE50 treatment than with lovastatin. This result was also observed in the cell division or motility related cytoskeleton protein coding genes, eg, CKAP2, ANLN, KIF11, -14, HMMR, TUBA1C, FRMD8. However, LAMP3, TUBG2, and COL16A1 demonstrated earlier repression in the GBE treatment group.

\section{Acknowledgments}

This work was financially supported by grants from the Chinese National High Tech Program (863-2003AA2032) and the Development Projects of Shanghai Commission of Science and Technology (03DZ19551, 05DZ19738, 06DZ19727).

We thank Hua-sheng XIAO, Zhi-dong ZHU, Jun-song HAN, Kai SONG, and Huai-guang SONG of the SBC for their technical support and constructive comments. We also thank Dr Qing ZHANG of Shanghai Institute of Plant Physiology and Ecology for help with liquid scintillation measurements. We thank Qi GAO and Guo-an ZHANG of Shanghai Xingling Pharmaceutical Co for providing the Ginkgo biloba extract products and their support.

\section{Author contribution}

Zuo-quan XIE and Lu ZHANG designed and conducted biochemistry measurements, RT-PCR, Western blot, and data exploration; Sai YE cultured the cells; Yi QU, Qi WANG, Yang GAO, and Ji ZHANG analyzed the data; Li-bo LIN performed the microarray experiment; Gai LIANG and Hui WANG performed the HMG-CoA reductase activity assays; Guo-ping ZHAO commented on experimental data; Qing-hua ZHANG designed the experiments, examined the data and wrote the manuscript.

\section{References}

1 Sharpless KE, Thomas JB, Christopher SJ, Greenberg RR, Sander LC, Schantz MM, et al. Standard reference materials for foods and dietary supplements. Anal Bioanal Chem 2007; 389: 171-8.

2 Ramassamy C, Longpre F, Christen Y. Ginkgo biloba extract (EGb 761) in Alzheimer's disease: is there any evidence? Curr Alzheimer Res 2007; 4: 253-62.

3 Luo Y, Smith JV, Paramasivam V, Burdick A, Curry KJ, Buford JP, et al. Inhibition of amyloid-beta aggregation and caspase-3 activation by the Ginkgo biloba extract EGb761. Proc Natl Acad Sci USA 2002; 99: 12197-202.

4 Bridi R, Crossetti FP, Steffen VM, Henriques AT. The antioxidant activity of standardized extract of Ginkgo biloba (EGb 761) in rats. Phytother Res 2001; 15: 449-51.

5 Liu CS, Cheng Y, Hu JF, Zhang W, Chen NH, Zhang JT. Comparison of antioxidant activities between salvianolic acid B and Ginkgo biloba extract (EGb 761). Acta pharmacol Sin 2006; 27: 1137-45.

6 Wu ZM, Yin XX, Ji L, Gao YY, Pan YM, Lu Q, et al. Ginkgo biloba extract prevents against apoptosis induced by high glucose in human lens epithelial cells. Acta Pharmacol Sin 2008; 29: 1042-50.

7 Mahady GB. Ginkgo biloba for the prevention and treatment of cardiovascular disease: a review of the literature. J Cardiovasc Nurs 2002; 16: 21-32.

8 Cho HJ, Nam KS. Inhibitory effect of ginkgolide B on platelet aggregation in a CAMP- and cGMP-dependent manner by activated MMP-9. J Biochem Mol Biol 2007; 40: 678-83.

9 Kudolo GB, Wang W, Barrientos J, Elrod R, Blodgett J. The ingestion of Ginkgo biloba extract (EGb 761) inhibits arachidonic acid-mediated platelet aggregation and thromboxane B2 production in healthy volunteers. J Herb Pharmacother 2004; 4: 13-26.

10 Yao ZX, Han Z, Drieu K, Papadopoulos V. Ginkgo biloba extract (Egb 761) inhibits beta-amyloid production by lowering free cholesterol levels. J Nutr Biochem 2004; 15: 749-56.

11 Igarashi K, Ohmuma M. Effects of isorhamnetin, rhamnetin, and quercetin on the concentrations of cholesterol and lipoperoxide in the serum and liver and on the blood and liver antioxidative enzyme activities of rats. Biosci Biotechnol Biochem 1995; 59: 595-601.

12 Lin SJ, Yang TH, Chen YH, Chen JW, Kwok CF, Shiao MS, et al. Effects of Ginkgo biloba extract on the proliferation of vascular smooth muscle cells in vitro and on intimal thickening and interleukin-1beta expression after balloon injury in cholesterol-fed rabbits in vivo. J Cell Biochem 2002; 85: 572-82.

13 Rodriguez M, Ringstad L, Schafer P, Just S, Hofer HW, Malmsten M, et al. Reduction of atherosclerotic nanoplaque formation and size by Ginkgo biloba (EGb 761) in cardiovascular high-risk patients. Atherosclerosis 2007; 192: 438-44.

14 Huang TH, Peng G, Li GQ, Yamahara J, Roufogalis BD, Li Y. Salacia oblonga root improves postprandial hyperlipidemia and hepatic steatosis in Zucker diabetic fatty rats: activation of PPAR-alpha. Toxicol Appl Pharmacol 2006; 210: 225-35.

15 Philipp BW, Shapiro DJ. Improved methods for the assay and activation of 3-hydroxy-3-methylglutaryl coenzyme A reductase. J Lipid Res 1979; 20: 588-93.

16 Huang J, Sheng HH, Shen T, Hu YJ, Xiao HS, Zhang Q, et al. Correlation between genomic DNA copy number alterations and transcriptional expression in hepatitis B virus-associated hepatocellular carcinoma. FEBS Lett 2006; 580: 3571-81.

17 Li RY, Zhang QH, Liu Z, Qiao J, Zhao SX, Shao L, et al. Effect of shortterm and long-term fasting on transcriptional regulation of metabolic genes in rat tissues. Biochem Biophys Res Commun 2006; 344: 562-70.

18 Yang YH, Dudoit S, Luu P, Lin DM, Peng V, Ngai J, et al. Normalization for cDNA microarray data: a robust composite method addressing single and multiple slide systematic variation. Nucleic Acids Res 2002; 30: e15.

19 Tusher VG, Tibshirani R, Chu G. Significance analysis of microarrays applied to the ionizing radiation response. Proc Natl Acad Sci USA 2001; 98: 5116-21.

20 Zheng PZ, Wang KK, Zhang QY, Huang QH, Du YZ, Zhang QH, et al. Systems analysis of transcriptome and proteome in retinoic acid/ arsenic trioxide-induced cell differentiation/apoptosis of promyelocytic leukemia. Proc Natl Acad Sci U S A 2005; 102: 7653-8.

21 Havsteen $\mathrm{BH}$. The biochemistry and medical significance of the flavonoids. Pharmacol Ther 2002; 96: 67-202.

22 Du Y, Wang K, Fang H, Li J, Xiao D, Zheng P, et al. Coordination of intrinsic, extrinsic, and endoplasmic reticulum-mediated apoptosis by imatinib mesylate combined with arsenic trioxide in chronic myeloid 
leukemia. Blood 2006; 107: 1582-90.

23 Watanabe CM, Wolffram S, Ader P, Rimbach G, Packer L, Maguire $\mathrm{JJ}$, et al. The in vivo neuromodulatory effects of the herbal medicine Ginkgo biloba. Proc Natl Acad Sci USA 2001; 98: 6577-80.

24 Eberle D, Hegarty B, Bossard P, Ferre P, Foufelle F. SREBP transcription factors: master regulators of lipid homeostasis. Biochimie 2004; 86: 839-48.

25 Yabe D, Brown MS, Goldstein JL. Insig-2, a second endoplasmic reticulum protein that binds SCAP and blocks export of sterol regulatory element-binding proteins. Proc Natl Acad Sci USA 2002; 99: 12753-8.

26 Wang J, Einarsson C, Murphy C, Parini P, Bjorkhem I, Gafvels M, et al. Studies on LXR- and FXR-mediated effects on cholesterol homeostasis in normal and cholic acid-depleted mice. J Lipid Res 2006; 47: 42130 .

27 Goodwin B, Jones SA, Price RR, Watson MA, McKee DD, Moore LB, et al. A regulatory cascade of the nuclear receptors FXR, SHP-1, and
LRH-1 represses bile acid biosynthesis. Mol Cell 2000; 6: 517-26.

28 Horton JD, Shah NA, Warrington JA, Anderson NN, Park SW, Brown MS, et al. Combined analysis of oligonucleotide microarray data from transgenic and knockout mice identifies direct SREBP target genes. Proc Natl Acad Sci USA 2003; 100: 12027-32.

29 Connelly MA, Williams DL. Scavenger receptor BI: a scavenger receptor with a mission to transport high density lipoprotein lipids. Curr Opin Lipidol 2004; 15: 287-95.

30 Qiu Y, Rui YC, Li TJ, Zhang L, Yao PY. Inhibitory effect of extracts of Ginkgo biloba leaves on VEGF-induced hyperpermeability of bovine coronary endothelial cells in vitro. Acta Pharmacol Sin 2004; 25 : 1306-11.

31 Gu X, Xie Z, Wang Q, Liu G, Qu Y, Zhang L, et al. Transcriptome profiling analysis reveals multiple modulatory effects of Ginkgo biloba extract in the liver of rats on a high-fat diet. Febs J 2009; 276: 1450-8. 